\title{
Tolerogenic bone marrow-derived dendritic cells induce neuroprotective regulatory $T$ cells in a model of Parkinson's disease
}

\author{
Charles R. Schutt ${ }^{1}$, Howard E. Gendelman ${ }^{1}$ and R. Lee Mosley ${ }^{1,2^{*}}$ (D)
}

\begin{abstract}
Background: Administration of granulocyte-macrophage colony-stimulating factor (GM-CSF) increases regulatory $T$ cell (Treg) number and function with control of neuroinflammation and neuronal protection in the 1-methyl-4-phenyl1,2,3,6-tetrahydropyridine (MPTP) model of Parkinson's disease (PD). Recently, we demonstrated in an early phase 1 clinical trial that GM-CSF also improves motor skills in PD patients. However, the mechanisms of Treg induction and its effects on neuroprotective responses remain unknown. As GM-CSF induces tolerogenic dendritic cells (DCs) that in turn convert conventional T cells to Tregs, the pathways for DC induction of Tregs were assessed.

Methods: Following differentiation, bone marrow-derived dendritic cells (BMDCs) were cultured in media or GM-CSF with or without post-culture stimulation with nitrated a-synuclein ( $\mathrm{N}$-a-Syn). Expression of cell surface co-stimulatory molecules and proinflammatory cytokines, and induction of Tregs were evaluated. The neuroprotective capacity of tolerogenic BMDCs was assessed by adoptive transfer to MPTP-intoxicated mice. The extent of neuroinflammation and numbers of surviving dopaminergic neurons were assessed in relation to Treg numbers.

Results: Co-culture of differentiated BMDCs with conventional T cells led to Treg induction. Stimulation of BMDCs with $\mathrm{N}$-a-Syn increased expression of co-stimulatory molecules and proinflammatory cytokines, with modest increases in Treg numbers. In contrast, continued culture of BMDCs with GM-CSF modestly altered expression of co-stimulatory molecules and proinflammatory cytokines and chemokines, but decreased Treg induction. Continued culture in GM-CSF and combined stimulation with N-a-Syn reduced Treg induction to the lowest levels. Adoptive transfer of tolerogenic BMDCs to MPTP-intoxicated mice increased splenic Tregs, attenuated neuroinflammatory responses, and protected nigrostriatal dopaminergic neurons.
\end{abstract}

Conclusions: GM-CSF acts broadly to differentiate DCs and affect immune transformation from effector to regulatory immune responses. DCs skew such immune responses by increasing Treg numbers and activities that serve to attenuate proinflammatory responses and augment neuroprotection.

Keywords: Mice, Dendritic cells, DCs, Regulatory T cells, Tregs, MPTP, Parkinson's disease, Neuroinflammation, Neurodegeneration

\footnotetext{
* Correspondence: rlmosley@unmc.edu

'Department of Pharmacology and Experimental Neuroscience, Center for Neurodegenerative Disorders, University of Nebraska Medical Center, Omaha, NE, USA

${ }^{2}$ Department of Pharmacology and Experimental Neuroscience, University of Nebraska Medical Center, 985930 Nebraska Medical Center, Omaha, NE 68198-5930, USA
}

(c) The Author(s). 2018 Open Access This article is distributed under the terms of the Creative Commons Attribution 4.0 International License (http://creativecommons.org/licenses/by/4.0/), which permits unrestricted use, distribution, and reproduction in any medium, provided you give appropriate credit to the original author(s) and the source, provide a link to the Creative Commons license, and indicate if changes were made. The Creative Commons Public Domain Dedication waiver (http://creativecommons.org/publicdomain/zero/1.0/) applies to the data made available in this article, unless otherwise stated. 


\section{Background}

Parkinson's disease (PD) is the most common neurodegenerative movement disorder and is caused by degeneration of dopaminergic neurons in the substantia nigra pars compacta. Loss of these neurons, their projections to the striatum, and dopamine neurotransmitter leads to resting tremor, postural instability, bradykinesia, and rigidity [1]. While a minority of PD cases result from defined mutations that initiate $\mathrm{PD}$, the majority of cases result from unknown events [2].

Both, the innate and adaptive arms of the immune system affect the neuropathology in PD. In PD patients $[3,4]$ and animal models [5-7], dopaminergic neuron loss is associated with increased numbers of activated microglia in the substantia nigra. These microglia produce proinflammatory mediators, such as interleukin-6 (IL-6), IL-1 $\beta$, and nitric oxide that are suggestive of a chronic inflammatory state in PD [8-10]. In addition, PD patients exhibit aberrant adaptive immunity and increases in CD4+ and CD8+ T cells infiltrating the substantia nigra $[3,5,11-16]$. In addition, percentages of CD4+ T cells are diminished in PD patients relative to controls without disease [11-16], but frequencies of Th1 and Th17 effector T cells (Teffs) are increased within the CD4+ population [17]. These Teffs recognize nitrated- $\alpha-$ synuclein (N- $\alpha-S y n)$ as modified self-protein and exacerbate neuroinflammation and neurodegeneration [18, 19]. Furthermore, depletion of CD4+ T cells, but not CD8+ T cells, inhibits susceptibility to MPTP, neuroinflammation, and neuronal loss, thus underscoring the importance of CD4+ T cells in affecting progressive neurodegeneration [18, 20]. In addition to increased numbers of proinflammatory Teffs, frequencies of Th2 and regulatory T cells (Tregs) as well as Treg activity are diminished in PD patients compared to healthy subjects $[13,17]$. Thus, for CD4+ T cells, opposite roles for $\mathrm{CD} 4+\mathrm{T}$ cells include proinflammatory, neurotoxic processes and anti-inflammatory, neuroprotective functions; both of which can dictate the tempo of PD disease progression. Moreover, the translational implications of these findings are noteworthy as pro-inflammatory immune functions in PD patients can be controlled by CD4+ T cells for potential clinical benefit [21, 22].

Dendritic cells (DCs) are the antigen presenting cell (APC) responsible for induction of both Teffs and Tregs [23-27]. Granulocyte-macrophage colony-stimulating factor (GM-CSF) induces tolerogenic DCs from bone marrow cells, which in turn increase Treg number and function [28-32]. Furthermore, adoptive transfer of GM-CSFinduced tolerogenic bone marrow-derived DCs (BMDCs), diminish autoimmune responses and protect from development of autoimmune sequelae. In autoimmune disorders, Treg induction by tolerogenic BMDCs is mediated by OX40L/Jag-1-dependent mechanisms $[33,34]$. In the 1methyl-4-phenyl-1,2,3,6-tetrahydropyridine (MPTP) PD model, administration of GM-CSF increases numbers of
Tregs without increasing the CD4+ T cell pool and attenuates neuroinflammation and neurodegeneration [35]. Additionally, Tregs from GM-CSF-treated mice are antiinflammatory and neuroprotective in MPTP-intoxicated mice. In a recent phase 1 clinical trial, administration of sargramostim (recombinant human GM-CSF) to PD patients increased Treg number and activity, improved UPDRS, III scores, and normalized motor initiation signaling deficits [36]. Together, these data demonstrate that GM-CSF diminishes neuroinflammation and loss of dopaminergic neurons by increasing Treg numbers and function. As T cells express few, if any, receptors for GM-CSF, Treg induction by GMCSF likely proceeds through indirect mechanisms. Moreover, those mechanisms must be achieved amid conditions of chronic exposure to GM-CSF, inflammation, and modified, misfolded proteins.

Our current study was designed to assess the effects of GM-CSF and modified $\alpha$-synuclein ( $\alpha$-Syn) on tolerogenic DCs and Treg induction. Herein, we show that GM-CSF-induced tolerogenic BMDCs lead to induction of Tregs from CD4+ T cells pools. Stimulation of BMDCs with $\mathrm{N}-\alpha-$ Syn upregulates expression of cytokine and chemokine genes and proteins, yet Treg induction capability, while diminished, remained at $88 \%$ of media controls. Further culture of BMDCs in GM-CSF significantly diminishes Treg induction to $\leq 55 \%$ of controls, regardless of stimulation with $\mathrm{N}-\alpha$-syn or intensity of proinflammatory mediator expression by BMDCs. In MPTP-intoxicated mice, adoptive transfer of tolerogenic BMDCs diminished numbers of reactive microglia and spared dopaminergic neurons along the nigrostriatal axis. While numbers of Tregs were not significantly increased after adoptive transfer of tolerogenic BMDCs to naïve mice, MPTP-intoxication after adoptive transfer significantly induced Treg transformation suggesting the necessity of acute inflammatory signaling to potentiate Treg induction. Together, the data provide a mechanism by which GM-CSF induces tolerogenic BMDCs that can drive $\mathrm{T}$ cell-to-Treg transformation, whereas further differentiation by continued exposure to GM-CSF and/or proinflammatory stimulation, diminish DC tolerogenic capacity. We posit that these processes provide a therapeutic strategy for BMDC-mediated control of Treg number and activity that lead to diminution of neuroinflammation and neurodegeneration in PD.

\section{Methods}

\section{Animals}

Male 6-8 week old mice C57BL/6J mice (Jackson Laboratories, Bar Harbor, ME) were used for all experiments. All procedures were performed in agreement with the National Institutes of Health guidelines and were approved by the University of Nebraska Medical Center Institutional Animal Care and Use Committee. 
Animals were maintained on a $12 \mathrm{~h}$ light/dark cycle and given food and water ad libitum.

\section{BMDC differentiation in vitro}

Femurs from 6 to 8 week old male C57BL/6J mice were removed and washed two times in Hanks' balanced salt solution (HBSS, Gibco, Waltham, MA) on ice and single cell suspensions of bone marrow cells (BMCs) were prepared by trituration. Red blood cells (RBCs) were lysed in ACK lysis buffer (Gibco) and washed in HBSS by centrifugation at $200 \mathrm{xg}$ for $10 \mathrm{~min}$. Cells were resuspended in R10 media [RPMI 1640 (Gibco) supplemented with $10 \%$ heat inactivated fetal bovine serum (Sigma, St. Louis, MO), $100 \mathrm{U}$ penicillin, $100 \mu \mathrm{g} / \mathrm{ml}$ streptomycin (Gibco), 10 mM HEPES (Hyclone, Logan, UT), 2 mM Lglutamine (Gibco), and $55 \mathrm{nM}$ 2-mercaptoethanol (Sigma)], and $4 \times 10^{6}$ cells were cultured in $4 \mathrm{mls}$ of R10 with $20 \mathrm{ng} / \mathrm{ml}$ of mouse recombinant GM-CSF (PeproTech, Rocky Hill, NJ) at $37{ }^{\circ} \mathrm{C}, 5 \% \mathrm{CO}_{2}$ for 4 days. On days 4 and 6 , used media was removed, the nonadherent cells harvested, and returned to culture with adherent cells in $4 \mathrm{mls}$ R10 media supplemented with $20 \mathrm{ng} / \mathrm{ml} \mathrm{GM-CSF}$. On day 8, media was removed, cells washed and cultured in either R10 media alone or supplemented with $40 \mathrm{ng} / \mathrm{ml}$ recombinant mouse GM-CSF. On day 10, half of the BMDCs cultured in R10 media alone or R10 supplement with GM-CSF were stimulated with $30 \mu \mathrm{g} / \mathrm{ml}$ recombinant $\mathrm{N}-\alpha-$ Syn [18] and cultured for $6 \mathrm{~h}$ for RNA isolation or $24 \mathrm{~h}$ for flow cytometric analysis of cells and supernatants for cytokine and chemokines. Thus, groups include GM-CSF-induced BMDCs further treated with 1) R10 media, 2) $20 \mathrm{ng} / \mathrm{ml}$ GM-CSF in R10 media, 3) R10 media followed by stimulation with $30 \mu \mathrm{g} / \mathrm{ml} \mathrm{N}-\alpha-S y n$, and 4) $20 \mathrm{ng} / \mathrm{ml} \mathrm{GM-CSF}$ in R10 media followed by stimulation with $30 \mu \mathrm{g} / \mathrm{ml} \mathrm{N}$ $\alpha$-Syn. The timing of GM-CSF culture and N- $\alpha$-Syn stimulation was chosen to affect maximal immune responses (data not shown).

\section{Isolation RNA, CDNA conversion and PCR arrays}

Six hours after $\mathrm{N}-\alpha-$-Syn stimulation, BMDCs were harvested, washed, and RNA isolated using the Rneasy mini kit (Qiagen, Germantown, MD) by the manufacturer's protocol. RNA concentration was determined by UV spectroscopy at $260 \mathrm{~nm}$ and $280 \mathrm{~nm}$ (ND-100 Nanodrop spectrophotometer, Thermo Scientific, Waltham, MA). Five hundred nanograms of RNA was converted to cDNA using the RevertAID first strand cDNA synthesis kit (Thermo Scientific) following the manufacturer's protocol. cDNA was added to molecular grade water (Invitrogen, Carlsbad, CA) and $2 \times \mathrm{RT}^{2}$ SYBR green mastermix (Qiagen), and $25 \mu \mathrm{l}$ of the mixture was added to each well of a Mouse Inflammatory Response and Autoimmunity array (PAMM-077ZA). PCR was performed in Eppendorf Realplex 2S Mastercycler starting at $95^{\circ} \mathrm{C}$ for $10 \mathrm{~min}$ followed by 40 cycles of $95^{\circ}$ $\mathrm{C}$ for $15 \mathrm{~s}$ and $60^{\circ} \mathrm{C}$ for $1 \mathrm{~min}$. After 40 cycles, melting curve analysis was performed. The $\mathrm{Ct}$ values were determined and the $\Delta \Delta \mathrm{Ct}$ method was used to determine fold changes relative to cDNA derived from media cultured, unstimulated BMDCs samples using $\mathrm{RT}^{2}$ Profiler PCR array data analysis version 3.5.

\section{Flow cytometry}

Twenty-four hours after culture with GM-CSF and/or $\mathrm{N}-\alpha-$ Syn stimulation, BMDCs were detached by scraping, washed, and resuspended in $10 \mu \mathrm{g} / \mathrm{ml}$ rat gamma globulin in flow staining buffer (FSB) $(0.5 \%$ bovine serum albumin (BSA) and $0.1 \%$ sodium azide in DPBS) for 40-60 min on ice to block Fc receptors. BMDCs were stained with the following mixture of AlexaFluor 488-anti-CD11c, PECy7-anti-CD11b, PE-anti-Jagged-1, APC-anti-OX40L, AlexaFluor 700-anti-MHC II, eFluor 450-anti-CD86, eFluor 710-anti-CD39 (eBioscience, San Diego, CA) and APC-Vio 770-anti-CD73 (Miltenyi Biotec, Auburn, CA) for $30 \mathrm{~min}$ at $4{ }^{\circ} \mathrm{C}$. Cells were washed two times in FSB and were fixed with $1 \%$ formaldehyde in DPBS. Samples were analyzed with a BD LSR II flow cytometer and FACSDiva software (BD biosciences, San Jose, CA) at the University of Nebraska Medical Center Flow Cytometry Research Facility. From the single cell-gated population, the percentages of positive for CD11c and CD11b were determined by drawing a gate that comprised $98 \%$ of the isotype control as negative. The geometric mean fluorescent intensity (MFI) of each surface marker was determined for CD11c+ cells.

\section{Luminex array}

After $24 \mathrm{~h}$ of culture with GM-CSF and/or N- $\alpha$-Syn stimulation of BMDCs, the supernatant was removed and clarified by centrifugation at 10,000 xg for $5 \mathrm{~min}$. Cytokine and chemokine concentrations were determined by Luminex xMAP Mouse cytokine and chemokine magnetic bead kit (Millipore, Billerica, MA) according to the manufacturer's protocol. Briefly, $25 \mu \mathrm{l}$ of supernatant from each of the 7 replicates for all treatment groups was added to a 96-well plate in duplicate or triplicate. To each sample or standard was added $25 \mu \mathrm{l}$ containing antibodies to IFN $\gamma$, IL- $1 \alpha$, IL-1 $\beta$, IL-2, IL-4, IL-5, IL-6, IL-7, IL-9, IL-10, IL-12p40, IL-12p70, IL-13, Lix, IL-15, IL-17, IP-10, MIP-2, MIG, RANTES, and TNF- $\alpha$ and incubated at $4{ }^{\circ} \mathrm{C}$ overnight. The plates were washed two times, detection antibodies added, incubated at room temperature (RT) for $60 \mathrm{~min}$, streptavidin-PE was added, and incubated at RT for $30 \mathrm{~min}$. The plate was washed two more times and analyzed with the Millipore Magpix system with Luminex 
Xponent 4.2 software. The concentration for each protein was determined from a standard curve.

\section{Isolation of CD4+ cells and co-culture}

For BMDC and CD4+ T cell co-culture, GM-CSF-induced BMDCs were harvested after culture in R10 media alone or R10 media supplemented with GM-CSF, unstimulated, or stimulated with $30 \mu \mathrm{g} / \mathrm{ml} \mathrm{N}-\alpha$-Syn. CD4+ cells $(93 \%$ CD4+CD25-Foxp3- and 2\% CD4+CD25 ${ }^{\text {hi }}$ Foxp3+) were isolated from spleens of C57BL/6J mice using the Miltenyi $\mathrm{CD} 4+$ negative selection kit (Miltenyi Biotech). Into the wells of a 24-well plate, $2 \times 10^{6} \mathrm{CD} 4+$ cells and $1 \times 10^{6}$ BMDCs were combined and incubated at $37{ }^{\circ} \mathrm{C}$ with $5 \%$ $\mathrm{CO}_{2}$ for 5 days. Non-adherent cells were removed and stained with PECy7-anti-CD4 and PE-anti-CD25 (eBioscience) and cells were permeabilized and fixed using the eBioscience Foxp3/transcription factor staining buffer set according to the manufacturer's protocol for $1 \mathrm{~h}$ prior to staining with APC-anti-Foxp3(eBioscience). Cells were analyzed with a LSR II flow cytometer (BD). Using FACSDIVA software (BD), single cells were gated to include CD4+ T cells, quadrants were set to include $98 \%$ of the isotype control, and the percentages of CD25 ${ }^{\text {hi }}$ Foxp3+ Tregs were determined.

\section{Treg functional assay}

The ability of Tregs to suppress the proliferation of CFSElabelled CD4+CD25- $T$ responder cells (Tresps) was performed as described previously [13, 37]. Briefly, CD4 +CD25- and CD4+CD25+ T cells were isolated using the Treg isolation kit (Miltenyi) from mouse spleens and from non-adherent cells after 5 days of co-culture of mediacultured, unstimulated BMDCs and CD4+ T cells. Splenic CD4+CD25- Tresps were labelled with CFSE (CellTrace Cell Proliferation Kit, Thermo Fisher, Waltham, MA) according to the manufacturer's protocol. In a 96-well $U$ bottom plate, $50,000 \mathrm{CD} 4+\mathrm{CD} 25+$ Tregs were diluted by serial 2-fold dilutions. To each well was added 50,000 CFSE-labelled CD4+CD25- Tresps, to yield Tresp:Treg ratios of 1:1, 1:0.5, 1:0.25, and 1:0.125. Each well received 50,000 Dynabeads mouse transactivator CD3/CD28 beads (Gibco) and the 96-well plate was incubated at $37^{\circ} \mathrm{C}, 5 \%$ $\mathrm{CO}_{2}$ for 3 days. The cells were fixed by removing half the media and adding in $1 \%$ formaldehyde in DPBS prior to flow cytometric analysis using a LSR II flow cytometer and FACSDIVA software (BD).

\section{MPTP and adoptive transfer}

Media-cultured, unstimulated tolerogenic BMDCs were prepared by culture of BMCs in $20 \mathrm{ng} / \mathrm{ml}$ GM-CSF for 8 days followed by 3 days of culture in R10 media alone. To male C57BL/6J mice, $1.5 \times 10^{6}$ BMDCs in $250 \mu \mathrm{l}$ of DPBS was injected intravenously (i.v.) into the tail vein at two and one week prior to MPTP intoxication. Mice were treated with 4 doses of either $10 \mathrm{ml} / \mathrm{kg}$ DPBS (Gibco) or $16 \mathrm{mg}$ free base MPTP (MPTP-HCl, SigmaAldrich, St. Louis, $\mathrm{MO}) / \mathrm{kg}$ with each dose administered subcutaneously (s.c.) every 2 h. MPTP safety and handling protocols were followed [38].

\section{Perfusion and immunohistochemistry for Mac-1 and tyrosine hydroxylase (TH)}

Mice were sacrificed 2 days post MPTP intoxication to assess neuroinflammation and 7 days post MPTP to assess neuronal survival [35, 37]. Briefly, mice were terminally anesthetized with pentobarbital (Vortech, Dearborn, MI), transcardially perfused with DPBS, and fixed with $4 \%$ paraformaldehyde/DPBS. Brains were removed, post-fixed for $24 \mathrm{~h}$ in $4 \%$ paraformaldehyde, cryoprotected for 2 days in 30\% sucrose/DPBS, and snap-frozen. Tissues were cryosectioned at $30 \mu \mathrm{m}$ sections through the striatum and midbrain containing the substantia nigra and processed for immunohistochemistry $[35,37]$. Free-floating sections were blocked of endogenous peroxidases with $3 \%$ hydrogen peroxide and non-specific activity in 5\% normal goat serum (Vector Laboratories, Burlingame, CA). Blocked sections were reacted with anti-TH (EMD/Milipore, Burlington, MA) at 1:2000 dilution for striatal sections and 1:1000 dilution for substantia nigra sections. After $48 \mathrm{~h}$, sections were washed and reacted with 1:400 dilution of goatanti-rabbit secondary antibody (Vector Laboratories) followed by $\mathrm{ABC}$ biotin-avidin peroxidase solution (Vector Laboratories) prior to color generation with 3,3'-diaminobenzidine (DAB, Sigma). Sections containing substantia nigra were counter stained for Nissl substance. For Mac-1 staining, sections were incubated with a 1:500 dilution of anti-Mac-1 primary antibody (BioRad, Hercules, CA) overnight. Sections were washed and reacted with 1:500 dilution of biotinylated rabbit anti-rat antibody (Vector laboratories) followed $A B C$ biotinavidin peroxidase solution (Vector Laboratories) prior to color generation with DAB. Numbers of dopaminergic neurons $(\mathrm{TH}+\mathrm{Nissl}+)$, non-dopaminergic neurons $(\mathrm{TH}-$ Nissl+), and reactive microglia (amoeboid Mac-1+) were estimated by stereological analyses analysis using the optical fractionator module of StereoInvestigator (MBF Bioscience, Williston, VT) $[35,37]$. Densities of $\mathrm{TH}+$ striatal termini were determined using digital densitometry using ImageJ as described $[35,37]$.

\section{Isolation of RNA from midbrain for PCR array}

Two days after MPTP intoxication, mice were sacrificed, brains quickly removed, hemisected, midbrain dissected, placed in RNAlater (Thermo Fisher), tissues weighed, and flash frozen at $-80{ }^{\circ} \mathrm{C}$. To isolate RNA, midbrains were homogenized in $350 \mu \mathrm{l} \beta$-mercaptoethanol-supplemented RLT buffer (Qiagen) for every $30 \mathrm{mg}$ tissue. Tissues were 
sequentially drawn up and down through 18, 20 and 27 Ga needles. RNA was isolated, converted to cDNA and assessed using Mouse Inflammatory Response and Autoimmunity PCR arrays as described.

\section{Statistics}

Statistics were performed using Prism GraphPad version 6. Means and SEM were determined for release of cytokines from BMDCs, relative changes in mean fluorescent intensity (MFI) in the flow markers on BMDCs, Treg frequency in the $\mathrm{CD} 4+$ population, and Mac-1+ microglia. For $\mathrm{TH}+$ neuron counts and striatal densities, means and SEM were determined for values within the 99\% confidence interval. For all analyses, one-way ANOVAs were performed followed by the appropriate posthoc test adjusted for multiple comparisons. A $p$ value less than or equal to 0.05 was selected as significant.

\section{Results}

\section{GM-CSF and BMDCs}

Because tolerogenic DCs exhibit decreased expression of proinflammatory cytokines in response to maturation stimuli $[39,40]$, we tested the expression of costimulatory molecules to determine whether GM-CSF mitigates these responses. Bone marrow cells were cultured for 8 days in $20 \mathrm{ng} / \mathrm{ml} \mathrm{GM-CSF}$ to produce immature bone marrow-derived dendritic cells (BMDCs). Immature BMDCs were $\geq 95 \% \mathrm{CD} 11 \mathrm{~b}+\mathrm{CD} 11 \mathrm{c}+$ (data not shown). To assess cellular phenotypic changes beyond the initial 8 days of culture, immature BMDCs were maintained in media alone or supplemented with GM-CSF for 2 days and/or stimulated with N- $\alpha$-Syn for 1 day. Frequencies and fluorescent intensities of cell surface markers were assessed by flow cytometric analysis. Frequencies of cells that express the dendritic cell markers $\mathrm{CD} 11 \mathrm{~b}$ and $\mathrm{CD} 11 \mathrm{c}$ showed little change, if any, regardless of culture conditions (Fig. 1a). CD11b expression was retained by $\geq 97 \%$ of the BMDCs regardless of treatment. Greater than $85 \%$ of immature BMDCs expressed CD11c after culture in media, GM-CSF, or stimulation with $\mathrm{N}-\alpha-$ Syn, while culture in GM-CSF and $\mathrm{N}-\alpha-$ Syn stimulation reduced the number of CD11c+ BMDCs to 77\% (Fig. 1a). This was confirmed by loss in the MFI of BMDCs expressing CD11c (Fig. 1b and c). Overall, virtually all BMDCs were myeloid DCs that stably expressed CD11b and CD11c independent of culture conditions.

We next tested whether continued GM-CSF exposure and/or stimulation with $\mathrm{N}-\alpha$-Syn induced phenotypic changes of co-stimulatory and regulatory molecules by evaluating mean fluorescent intensity (MFI) compared to media treatment (Fig. 1b and c). Notably, fluorescent intensities associated with cell surface expression were normally distributed as shown for representative histograms (Fig. 1b). Gating on CD11b+CD11c+ BMDCs, the geometric MFIs of MHC II and CD86 expression were determined. Expression of MHC II was significantly elevated after $\mathrm{N}-\alpha$-Syn stimulation compared to culture in media alone or GM-CSF (Fig. 1c). Interestingly, continued culture with GM-CSF prior to $\mathrm{N}-\alpha$-Syn stimulation significantly diminished MHC II expression compared to stimulation with $\mathrm{N}-\alpha-$ Syn alone. Compared to culture in media or GM-CSF alone, MFI of CD86 was significantly elevated by BMDCs stimulated with $\mathrm{N}-\alpha$-Syn or treated with GM-CSF and $N-\alpha-S y n$ combined, which was significantly diminished from BMDCs stimulated with $\mathrm{N}-\alpha-\mathrm{Syn}$ alone.

The expression of co-stimulatory molecules associated with anti-inflammatory or regulatory activities were also tested as those molecules could skew naïve CD4+ T cells towards Th2 and Treg transformation. The surface expression of OX40L and Jag-1 has been linked to Treg induction [33, 34]. OX40L expression was slightly, though significantly altered by treatment with $\mathrm{N}-\alpha$-syn with or without prior exposure to GM-CSF (Fig. 1b and c). Compared to media control, Jag-1 expression was significantly increased by all other culture conditions. Stimulation with $\mathrm{N}-\alpha$-Syn increased expression by 1.5 -fold, and continued cultivation with GM-CSF by 1.8 -fold, while treatment with both increased expression by 2.5 -fold. Together, these data show that OX40L expression showed limited change by any culture condition; however, Jag- 1 expression was increased by treatment with GM-CSF and/or N- $\alpha$-Syn.

Lastly, we tested the expression of surface ATPases since metabolism of extracellular ATP to adenosine is associated with the generation of Tregs [41]. CD39 is an ectonuclease which metabolizes ATP to AMP and CD73 is a surface expressed enzyme which metabolizes AMP to adenosine. Stimulation with $\mathrm{N}-\alpha$-syn with or without further GMCSF exposure diminished the expression of CD39 by 37 and $32 \%$, respectively compared to treatment with media alone (Fig. 1b and c). In contrast, further exposure to GMCSF regardless of stimulation with $\mathrm{N}-\alpha$-Syn increased CD73 expression by at least 1.8 -fold compared to media controls, whereas stimulation with $\mathrm{N}-\alpha$-Syn alone yielded no significant increase in CD73 expression. This suggested that stimulation with $\mathrm{N}-\alpha$-Syn reduces some regulatory components of Treg formation, whereas GM-CSF may increase others. Together, these results support the notion that GM-CSF affects the BMDC tolerogenic state defined by diminished surface expression of MHC II and CD86 as well as increased Jag-1 and CD73 expression and that N$\alpha$-Syn stimulation and GM-CSF may increase or decrease co-stimulatory or regulatory components necessary for Treg induction.

$\mathrm{N}$-a-Syn stimulated BMDCs with or without culture in GMCSF potentiates an inflammatory state

As N- $\alpha$-Syn stimulation increases BMDC co-stimulatory molecule expression, we tested the effects of GM-CSF, 

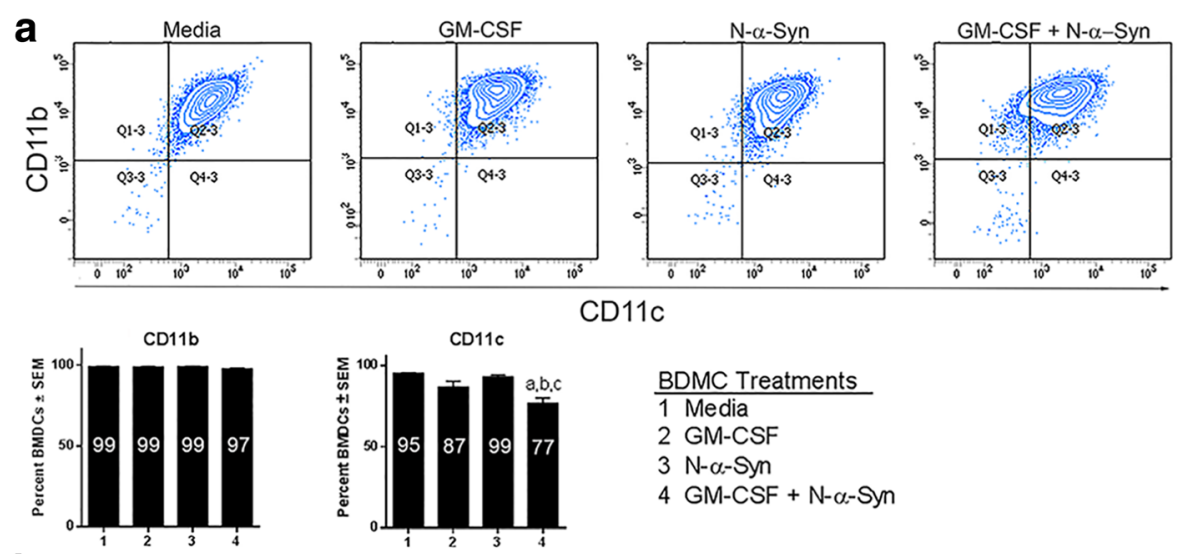

BDMC Treatments

1 Media

2 GM-CSF

$3 \mathrm{~N}-\alpha-\mathrm{Syn}$

$4 \mathrm{GM}-\mathrm{CSF}+\mathrm{N}-\alpha-\mathrm{Syn}$

b
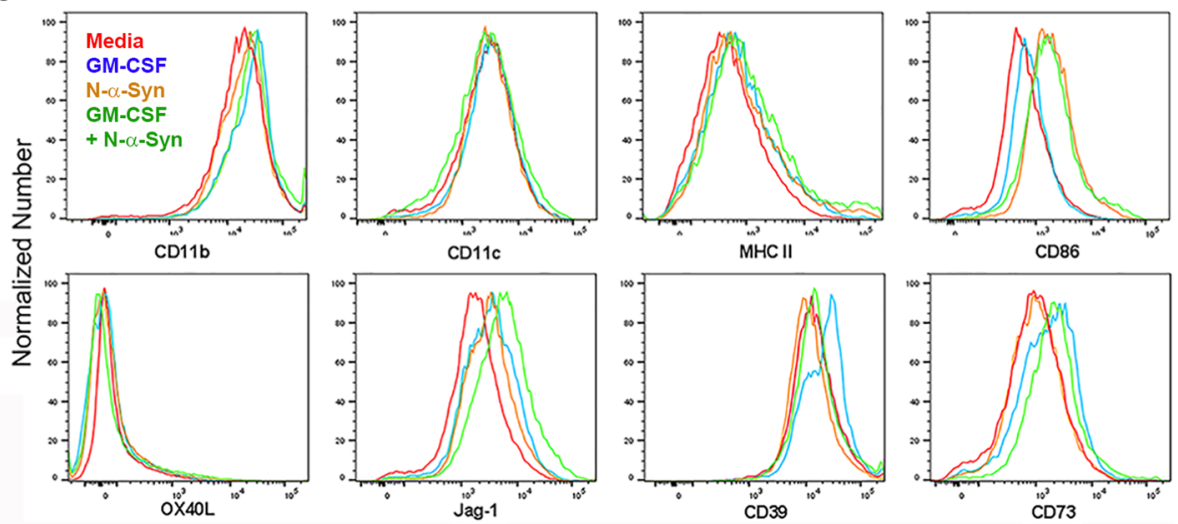

C
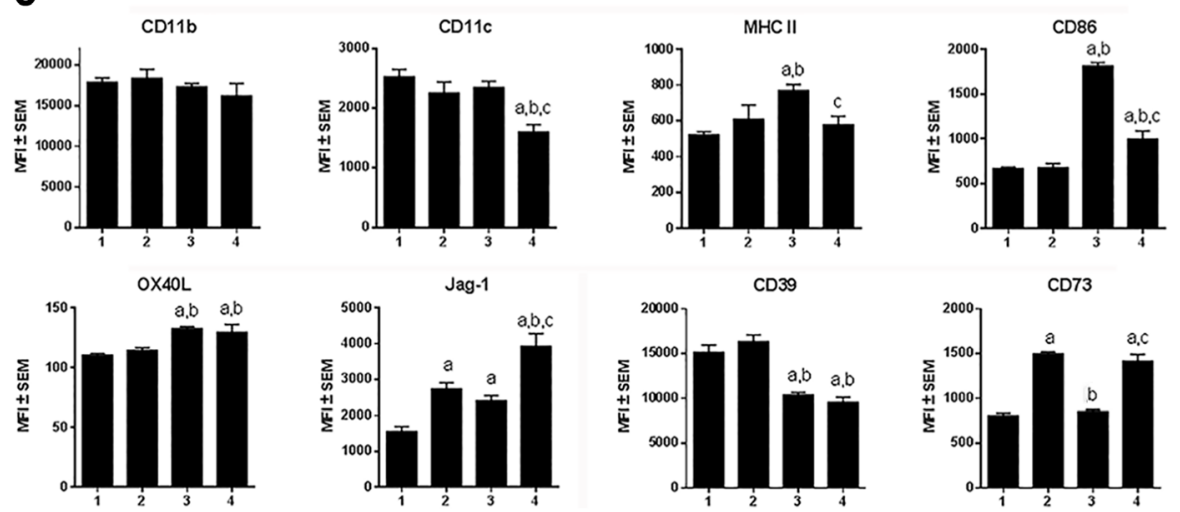

Fig. 1 Surface expression on BMDCs. GM-CSF-generated BMDCs were cultured in media alone or with $20 \mathrm{ng} / \mathrm{ml}$ GM-CSF for 2 days prior to stimulation with 30 mg/ml N-a-Syn for 1 day. Treatment groups were as follows: (1) media-cultured, unstimulated BMDCs; (2) GM-CSF-cultured, unstimulated BMDCs; (3) media-cultured, N-a-Syn-stimulated BMDCs; and (4) GM-CSF-cultured, N-a-Syn-stimulated BMDCs. Cells were harvested and reacted with antibodies to detect expression of CD11C, CD11b, MHC II, CD86, OX40L, Jag-1, CD39 and CD73, then evaluated by flow cytometric analysis. a Cells were gated by forward scatter area vs height to include only single cells and CD11b+CD11c+ BMDC populations were identified. Percentages of cells expressing CD11b or CD11c were determined and the mean percentages of single cells positive for each marker are shown within the bars. (b and $\mathbf{c})$ BMDCs were gated to include the $\mathrm{CD} 11 \mathrm{~b}+\mathrm{CD} 11 \mathrm{c}+$ cell population and the geometric mean fluorescent intensity (MFI) was determined for expression of MHC II, CD86, OX40L, Jag-1, CD39, and CD73. b Overlays of representative histograms are shown for BMDCs treated with media (red), GM-CSF (blue), N-a-Syn (orange), or GM-CSF + N-a-Syn (green). c Histograms represent the means \pm SEM for 7 replicates from each treatment group. The means were compared by one-way ANOVA and Newman-Keuls post-hoc test whereby $p \leq .0 .05$ compared to BMDCs treated with ${ }^{a}$ media, ${ }^{b}$ GM-CSF, or ${ }^{\mathrm{C}} \mathrm{N}$-a-Syn

$\mathrm{N}-\alpha$-Syn, or both on cellular RNA immune profiles. cDNA from RNA was analyzed using a PCR array for regulation of proinflammatory cytokine and chemokine genes, and normalized to BMDCs cultured in media alone. Continuing culture of BMDCs in GM-CSF increased the expression by more than two-fold for $\mathrm{Il6}$, Cxcl9, Cxcl3, Ccl17, Sele, Ccl24, Cor1, Cxcr2, Tnfsf14, and $C c r 2$, but down-regulated by more than two-fold 
Cxcl10, Cd40, Tnf, Tlr1, and Bcl6 (Fig. 2). Stimulation of BMDCs with $\mathrm{N}-\alpha-\mathrm{Syn}$ with or without GM-CSF increased expression of maturation markers $\mathrm{Ccr} 7$ and Cebpb confirming that $\mathrm{N}-\alpha-$ Syn alone activated BMDCs. Also, $\mathrm{N}-\alpha-$ Syn stimulation increased expression of the proinflammatory genes Cxcl10, Il6, Il23a, Tnf, Ccl4, Cxcl1, Cxcl2, Il1a, Il1b, Il18, and Ifng. Several genes involved in Toll-like receptor (TLR) signaling including Tlr1, Tlr3, Tlr2, Cd14, Myd88, and Nfkb1 were increased following $\mathrm{N}-\alpha$-Syn stimulation while Tlr4 and Tlr5 were decreased. Moreover, $\mathrm{N}-\alpha$-Syn stimulation also increases Nos2 expression, the gene for inducible nitric oxide synthase. In contrast, several down-regulated genes by $\mathrm{N}-\alpha$-Syn stimulation included Ccr2, Fos, Cxcr4, Ilbra, Tnfsf14, Cxcr2, and Ccr1.

Compared to N- $\alpha$-Syn stimulation of BMDCs, continued culture with GM-CSF prior to N- $\alpha$-Syn treatment decreased expression of Cxcl10, Il6, Ptgs2, Tnf, Cxcl1, and Lta (Fig. 2). Conversely, genes whose expression increased were Il23a, Nos2, Illa, Cxcl11, Il1b, Cxcl3, Il10, and Ccl17. Cxcr4 and Fos were modestly down-regulated. Prolonged culture with GM-CSF prior to N- $\alpha$-Syn stimulation, increased expression of $T l r 2$ and decreased the expression of Tlr1, Tlr3, however Myd88, Cd14, and $N f k b 1$ were not changed. These changes demonstrate that continued culture with GM-CSF did not diminish the ability of BMDCs to respond to $\mathrm{N}-\alpha-\mathrm{Syn}$ stimulation, but rather altered the expression of select proinflammatory genes and may target specific genes expressed after stimulation.

To further test prolonged GM-CSF exposure and N- $\alpha$ Syn stimulation on BMDCs, we assessed cytokine and chemokine production from culture supernatants. Continued culture in GM-CSF produced few significant changes in cytokine or chemokine production with the exception of diminished MIP2 and increased IL-9 (Fig. 3). $\mathrm{N}-\alpha$-Syn stimulation in media alone significantly increased release of IL-1 $\beta$, IL-10, Lix, MIG, IL-6, IL-12p70, IL-13, IL-15, IFN- $\gamma$, RANTES, and TNF $\alpha$. Continued culture with GM-CSF prior to $\mathrm{N}-\alpha-$ Syn increased release of IL- $1 \alpha$, IL-1 $\beta$, IL-2, IL-5, IL-7, IL-9, IL-10, IL-12p40, IL-17, and IP-10, and decreased release of Lix and MIG compared to media control and N- $\alpha$-Syn stimulation. Culture of BMDCs with GM-CSF prior to $\mathrm{N}-\alpha-$ Syn stimulation did not affect production or release of pro-inflammatory cytokines. In addition, IL-10 was increased by continued GMCSF culture. Together, these data suggest that after induction of BMDCs by GM-CSF, further culture with or without GM-CSF does not change the cytokine and chemokine levels. However, stimulation of BMDCs with $\mathrm{N}-\alpha$-Syn, regardless of culture conditions elicits a proinflammatory profile. Moreover, whether $\mathrm{N}-\alpha$-Syn affects Treg induction by GM-CSF-induced tolerogenic DCs remains unanswered.

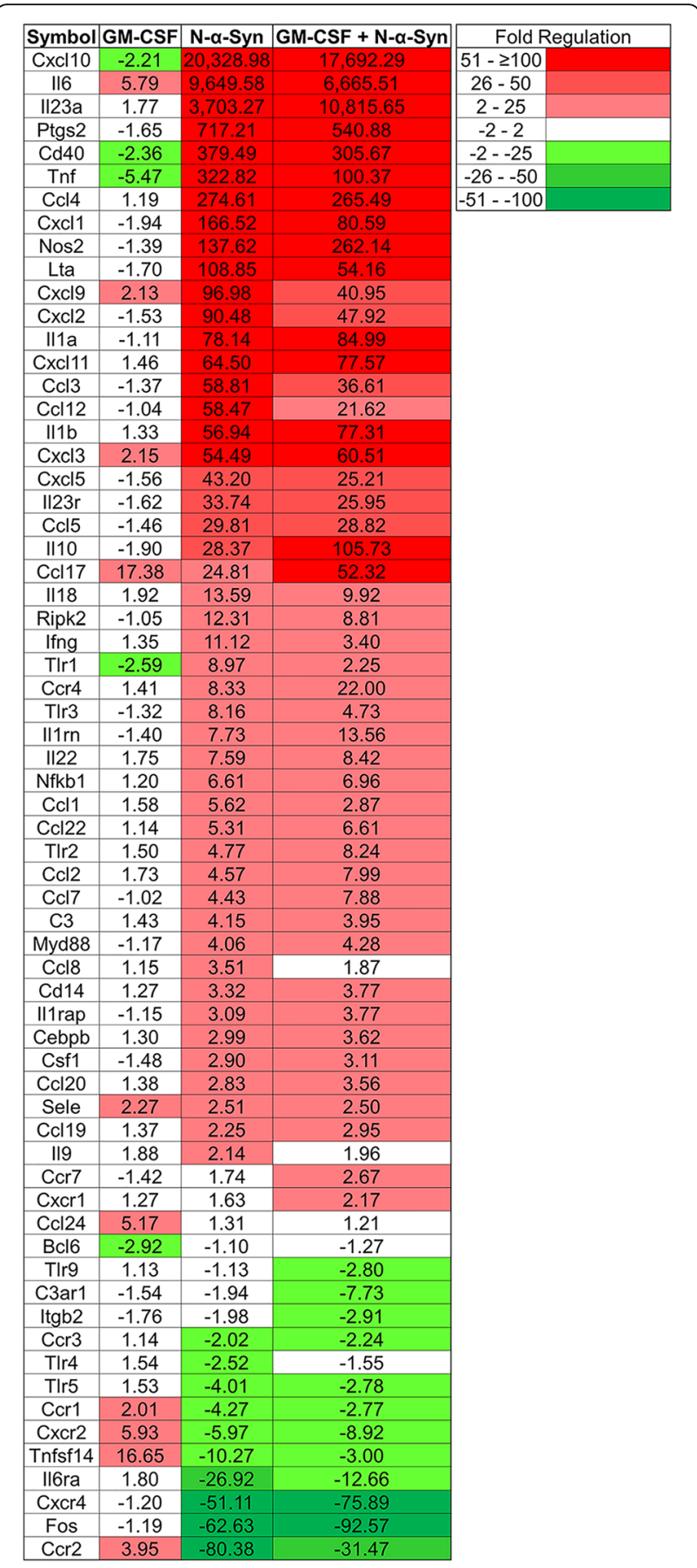

Fig. 2 Gene expression of GM-CSF, N-a-Syn, or GM-CSF/N-a-Syn-cultured BMDCs. GM-CSF-generated BMDCs were cultured for 2 days in media or $20 \mathrm{ng} / \mathrm{ml}$ GM-CSF (GM-CSF). BMDC cultures from each group were stimulated with $30 \mu \mathrm{g} / \mathrm{ml}$ N-a-Syn for $6 \mathrm{~h}$ ( $\mathbf{N}$-a-Syn or GM-CSF + N-aSyn, respectively). RNA was isolated, converted to CDNA and assessed by PCR arrays for proinflammatory genes. Gene expression from BMDCs from treatment groups was determined relative to BMDCs treated with media alone. Each treatment group was composed of 6 replicates and fold change was determined by SA Bioscience array software 


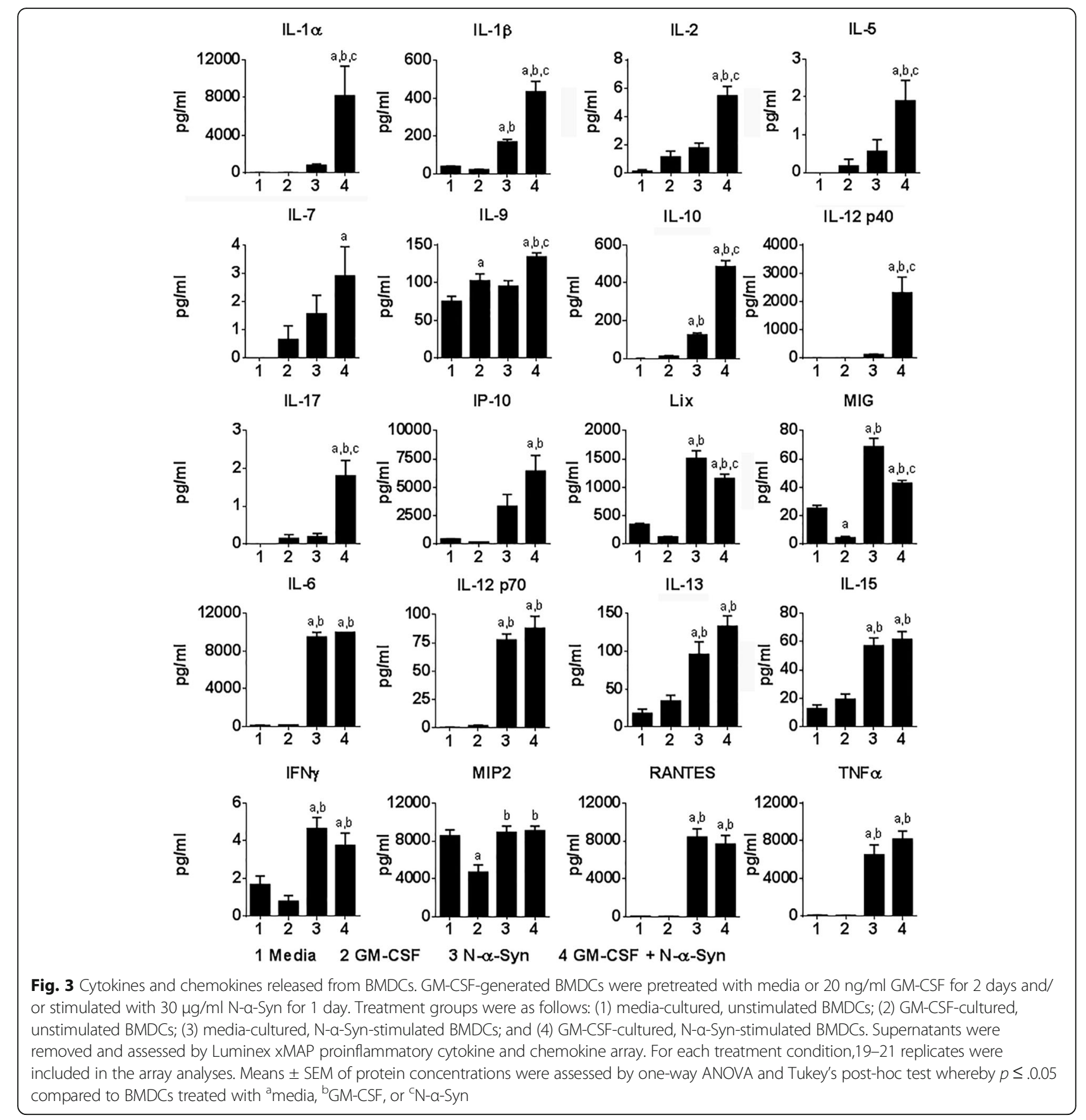

BMDC-mediated induction of Tregs diminishes with continued presence of GM-CSF

To determine culture conditions necessary for Treg induction by tolerogenic DCs and to test these processes, GM-CSF-induced BMDCs were co-cultured with CD4+ $\mathrm{T}$ cells from naïve mice for 5 days. After co-culture, non-adherent cells were analyzed by flow cytometric analysis to determine frequencies of Tregs (CD4+CD25 + Foxp3+). Co-culture of T cells with BMDCs regardless of conditions increased Treg frequencies within the CD4+ $\mathrm{T}$ cell population compared to within the initiating CD4+ isolates (Fig. 4a and b). Notably, T cells co-cultured with BMDCs in media alone generated a greater frequency of Tregs than any culture condition. Co-culture in the presence of N- $\alpha$-Syn induced levels of Tregs similar though significantly less than those of media controls. Co-culture of BMDCs and T cells in GM-CSF or GM-CSF and N- $\alpha-$ Syn combined produced Treg frequencies less than 55\% of those co-cultured in media alone (Fig. 4a and b). To test the role of classical $\mathrm{T}$ cell activation and signaling pathways, CD4+ T cells from naïve mice were stimulated with CD3/CD28 transactivator beads. While Treg frequencies 

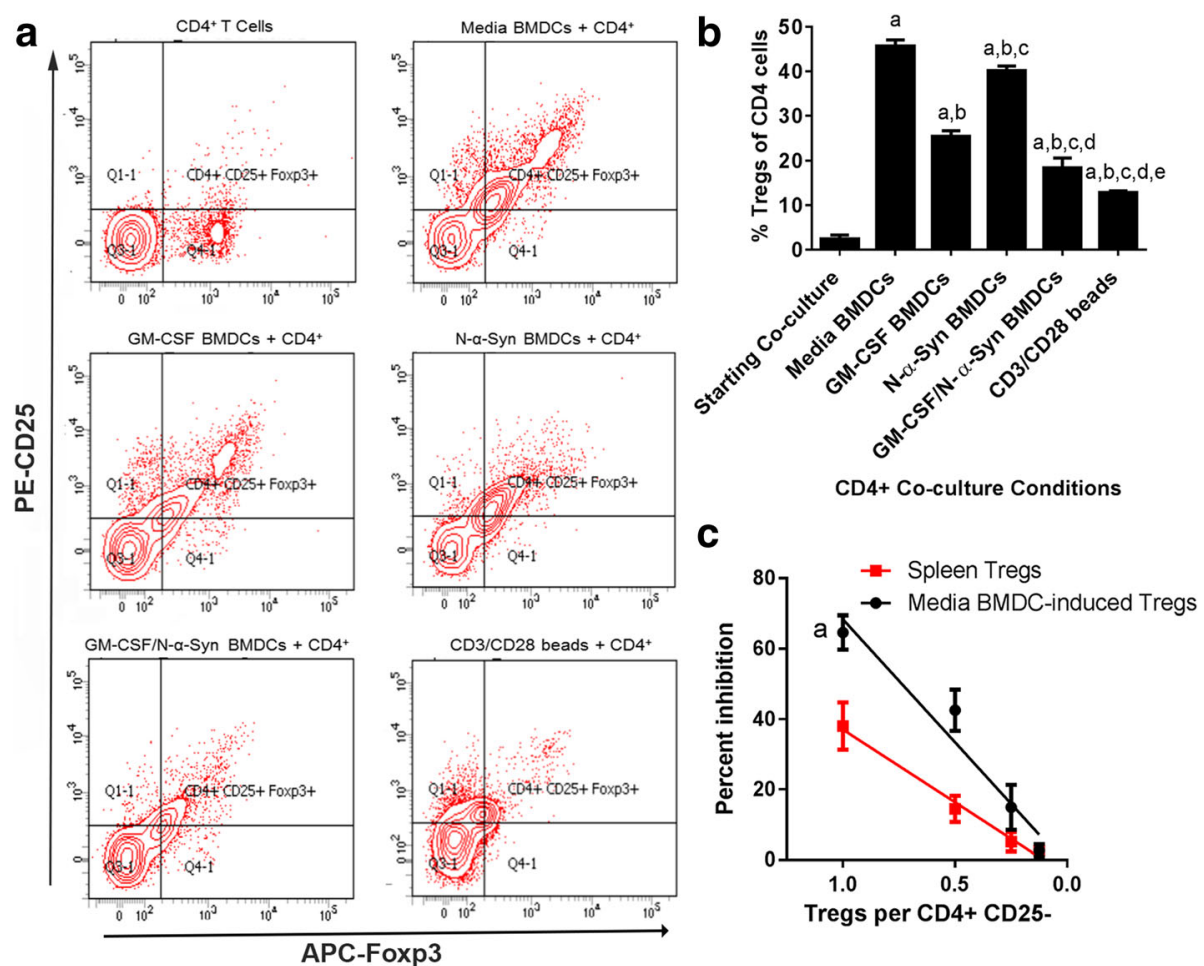

Fig. 4 BMDCs induce functional Tregs. GM-CSF-generated BMDCs were pretreated with media or $20 \mathrm{ng} / \mathrm{ml}$ GM-CSF for 2 days and/or stimulated with $30 \mu \mathrm{g} / \mathrm{ml} \mathrm{N}$-a-Syn for 1 day prior to co-culture for 5 days with CD4+ T cells. Non-adherent T cells were harvested, stained for expression of CD4, CD25, and Foxp3, and evaluated by flow cytometric analysis. CD4+ gate was drawn to include $>98 \%$ of the populations and quadrants were placed to include $98 \%$ of the isotype control. a Contour plots of flow cytometric analyses for expression of Foxp3 and CD25 by CD4+ T cells from 5 day co-cultures of BMDCs and CD4+CD25- T cells. b Quantitation of CD25+Foxp3+ Tregs within CD4+ T cell population from BMDC-CD4+ T cell co-cultures or treated with CD3/CD28 transactivation beads. Mean percentages \pm SEM of Tregs were determined for 3 replicate co-cultures and evaluated by one-way ANOVA followed by Newman-Keul's post-hoc test whereby $p \leq 0.05$ compared to ${ }^{a}$ starting CD4+ T cells; ${ }^{b}$ media-cultured BMDCs/CD4+ T cells; ${ }^{C} \mathrm{GM}$-CSF-cultured BMDCs/CD4+ T cells; ${ }^{\mathrm{d}}$ media-cultured, N-a-Syn-stimulated BMDCs/CD4+ T cells; and ${ }^{\mathrm{e}} \mathrm{GM}$-CSF cultured, Na-syn stimulated BMDCs/CD4+ T cells. $\mathbf{c}$ Tregs were enriched by magnetic bead selection for CD4+CD25+ T cells either from 5 day media cocultures of BMDCs/CD4+ T cells or from primary isolates of splenic T cells from naive mice. Tregs were diluted by serial 2-fold dilutions, added to CFSE-labelled CD4+CD25- cells, and stimulated with CD3/CD28 tansactivator beads for 3 days. Cells were harvested and assessed by flow cytometric analysis for Treg activity to suppress $T$ cell proliferation. Linear regression showed that Treg activity correlated with Treg dose for BMDC-induced Tregs $\left(r^{2}=0.7941, F=80.97, D F n=1, D F d=21, p<0.00001\right)$ and for primary splenic Tregs $\left(r^{2}=0.6815, F=47.07, D F n=1\right.$, $\mathrm{DFd}=22, p<0.0001)$. Additionally, comparison of the two regression analyses show that the lines are significantly different $(F=8.52, \mathrm{DFn}=1$, $\mathrm{DFd}=43, p=0.0056$

were significantly increased relative to initiating CD4+ T cell isolates, the levels were significantly less than any other treatment. Together, these results demonstrate that BMDCs can induce Tregs from CD4+ T cells. The presence of $\mathrm{N}-\alpha$-Syn during induction slightly diminishes Treg production despite increased levels of proinflammatory cytokines. However, co-culture in the presence of GMCSF, with or without $\mathrm{N}-\alpha-\mathrm{Syn}$, significantly diminishes Treg induction by 55 or $46 \%$, respectively, despite little, if any proinflammatory cytokines produced by culture in GM-CSF alone. The data also suggest that processes for BMDC-mediated induction of Tregs require variant signals than those generated by CD3/CD28-mediated activation and proliferation of $\mathrm{CD} 4+\mathrm{T}$ cells.

We next tested whether Tregs produced by BMDCs were functional. Non-adherent $\mathrm{T}$ cells from BMDC co- cultures were enriched for CD4+CD25+ T cells, seriallydiluted, co-cultured with CFSE-stained CD4+CD25Tresps, stimulated with CD3/CD28 transactivator beads, and $\mathrm{T}$ cell proliferation assessed. Also, fresh isolates of CD4 +CD25+ Tregs were enriched from spleens of naïve mice, and similarly assessed to compare functional capacities of Treg populations. Tregs from either source were capable of suppressing proliferation of Tresps in a dose dependent fashion (Fig. 4c). Notably, Tregs from BMDC co-cultures showed greater suppressive ability than primary Treg isolates. Together, these results demonstrated that BMDCs produce functional CD4+CD25+Foxp3+ Tregs.

\section{BMDCs are neuroprotective}

Prior studies demonstrated that Tregs are neuroprotective [35, 42-45]. Moreover, tolerogenic BMDCs induce 
Tregs in models of autoimmunity and neurodegeneration [28-32]. Thus, we tested whether BMDCs could protect dopaminergic neurons from MPTP intoxication. GM-CSF-differentiated BMDCs were cultured in media alone and adoptively transferred into mice one and two weeks prior to MPTP intoxication. Results were compared to those from mice treated with MPTP or PBS alone. Seven days after MPTP intoxication and resolution of cellular debris [46], numbers of surviving nigral $\mathrm{TH}+$ dopaminergic neuronal bodies and striatal termini were evaluated. Compared to MPTP-treated animals, increased numbers of $\mathrm{TH}+$ neurons in the substantia nigra and densities of striatal termini survived from animals in which BMDCs were adoptively transferred (Fig. 5).

As diminished numbers of reactive microglia correlate with dopaminergic neuroprotection [6, 13, 35, 37, 47, 48], we assessed the abilities of GM-CSF-generated BMDCs to affect neuroinflammation. Mice treated with PBS, MPTP, or BMDCs prior to MPTP were compared 3 days after MPTP intoxication; the time of peak neuroinflammation $[46,49]$. Adoptive transfer of BMDCs significantly decreased numbers of reactive microglia by $58 \%$ compared to MPTP-treated controls (Fig. 6). These data support the capacity of BMDCs to diminish neuroinflammatory processes during MPTP-induced neurodegeneration.

To further assess the effects of BMDC-mediated suppression of neuroinflammation, we tested proinflammatory gene expression from midbrains of mice treated with PBS, MPTP, or BMDCs and MPTP. Gene expression was compared relative to midbrains from PBS controls. MPTP intoxication increased the expression more than 2-fold of Ccl3, Cxcl10, Ccl4, Il1r1, Il1rn, Cebpb, Tlr2, and Csf1, and down-regulated by more than 2-fold C3ar1, Myd88, Tlr1, Ccl2, Ccr3. Ccr1, Tlr9, Ccl11, Cxcr4, Ccl25, Ccl12, Ripk2, and Tlr3 (Fig. 7a). Treatment with BMDCs by adoptive transfer and MPTP, increased by almost 2-fold the expression of Illrn, the antagonist for IL-1 receptor [50]. Of the genes downregulated by MPTP, expression of Ccl2, Ccl12, Ripk2, and Tlr3 was increased in BMDC-treated mice. In addition, adoptive transfer of BMDCs increased by more than 2-fold the proinflammatory genes Il6ra, Il17a, Tnf, and Il6 and antiinflammatory $I l 10$ gene. BMDCs also increased the expression of chemokine-related genes $\mathrm{Cxcl}$, Cxcr2, Ccl1, Cxcl1, Cxcr1, Cxcl3, Cxcl9, Ccr4, Ccr2, Ccl20, Ccl24, Cxcl5, and $\mathrm{Ccl}$. To better identify which genes are changed, midbrains of mice treated with BMDCs then MPTP intoxicated were compared to genes expressed in midbrains of mice treated with MPTP alone. Ingenuity Pathway Analysis showed 24 genes that expressions were changed by 2 -fold or more and were associated with inflammatory response (Fig. 7b). The pattern of expression was indicative of inflammation as indicated by increases in Tnf, Ccl11, Cxcl10, Cxcl6, Cxcr4, Ccr1, and $\mathrm{Ccr} 3$, and genes related to pathogen recognition such as Tlr1, Tlr2, Tlr3, Tlr9, Myd88, and Ripk2. Decreased

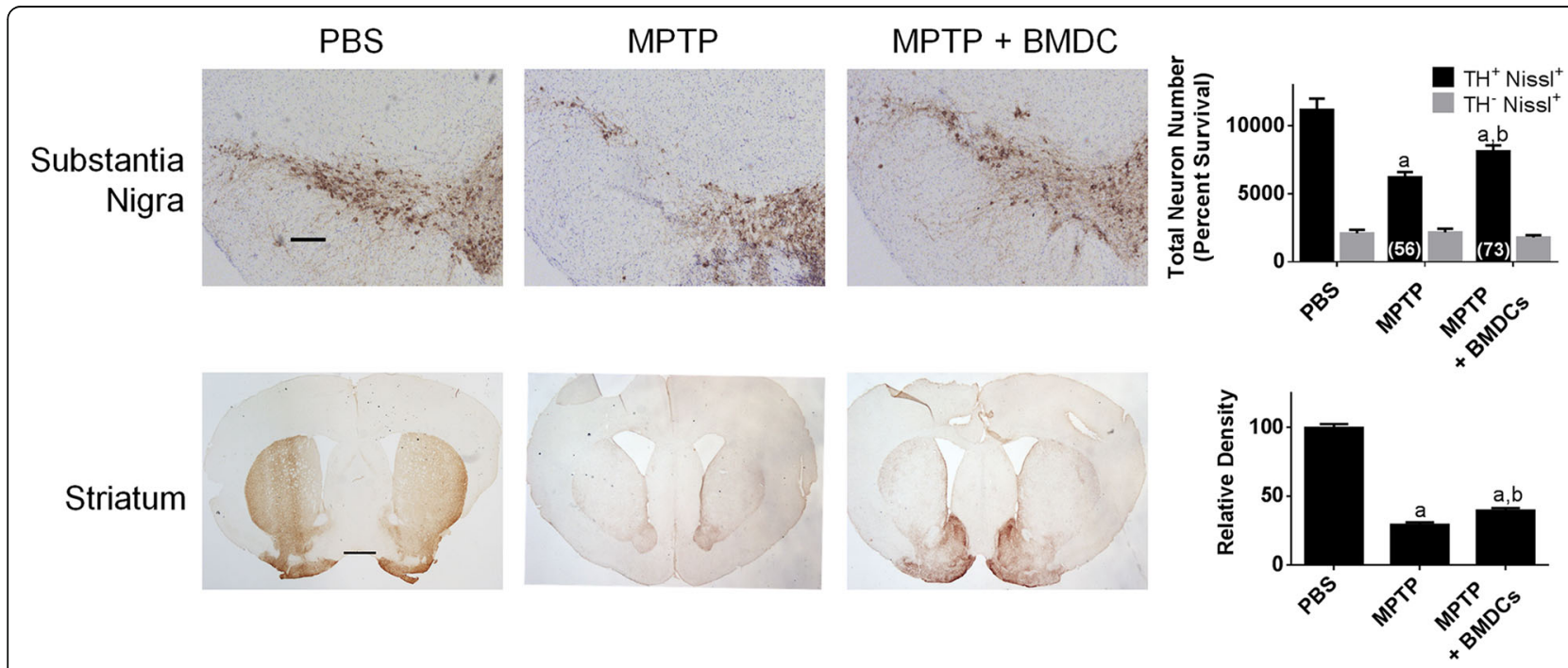

Fig. 5 BMDCs are neuroprotective in the MPTP mouse model. GM-CSF-generated BMDCs were cultured in media alone, harvested, and $1.5 \times 10^{6}$ in $0.25 \mathrm{mls}$ were transferred i.v. at one and two weeks prior to intoxication with four $16 \mathrm{mg} / \mathrm{kg}$ doses of MPTP. Mice that received PBS or MPTP alone served as controls. Seven days after MPTP intoxication, brains were removed, frozen, and cryosectioned at $30 \mu \mathrm{m} / \mathrm{section}$ to contain the substantia nigra and striatum. Sections were stained by immunohistochemistry for tyrosine hydroxylase (TH) and nigral sections were counter stained for Nissl substance. Scale bar is $200 \mu \mathrm{m}$. Total dopaminergic neurons (TH+Nissl+) and non-dopaminergic neurons (TH-Niss $/+)$ in the substantia nigra were estimated by stereological analysis for mice treated with PBS $(n=6)$, MPTP $(n=8)$, or BMDCs and MPTP $(n=7)$. Scale bar is $1 \mathrm{~mm}$. Density of TH termini in the striatum was determined for $1.4 \mathrm{~mm}^{2}$ area for 4-6 sections for each striatum from mice treated with PBS $(n=7)$, MPTP $(n=7)$, or BMDCs and MPTP $(n=6)$. Relative densities were normalized to that of the PBS control $(100 \%$ relative density). Means \pm SEM of total number of nigral neurons or means \pm SEM) of relative striatal TH densities were assessed by one-way ANOVA followed by Tukey's post hoc test whereby $p \leq 0.05$ compared to mice treated ${ }^{\text {aPBS }}$ or ${ }^{\mathrm{b}} \mathrm{MPTP}$ alone 


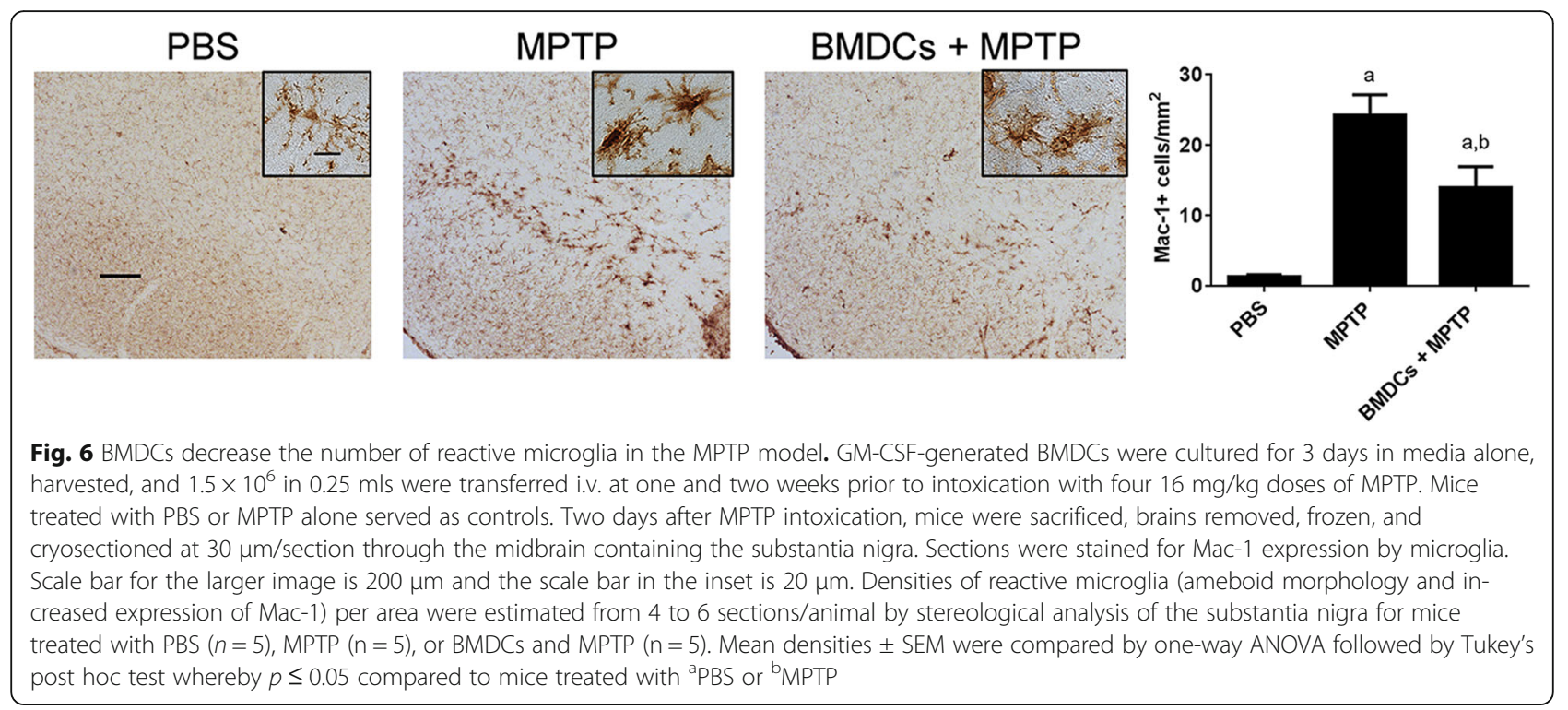

expression of Il1r1, Cebpb, Ccl4, and Ccl3l3, and increased expression of $\mathrm{Ccl} 2, \mathrm{Ccl} 24$, and Il1rn were indicative of an anti-inflammatory profile.

\section{BMDCs induce Tregs after MPTP intoxication}

We and others showed that in models of PD, GM-CSF is neuroprotective and that it increases Treg frequency and number as well as Treg activity in both PD and PD Models [35, 36, 51]. We thus assessed the effects of BMDCs to increase splenic Treg frequency in naïve mice and under neurodegenerative conditions. Seven days after serial weekly adoptive transfers of GM-CSF-derived BMDCs, flow cytometric analysis showed no change in overall CD4+ T cells, but showed decreased frequency of CD4+CD25+Foxp3+ Tregs (Fig. 8a). These results somewhat contrasted other results showing in vitro induction of Tregs by GM-CSF-matured BMDCs, either in the presence or absence of N- $\alpha$-Syn (Fig. 4b) and GM-CSFinduced Tregs in vivo in the context of ongoing immune responses, disease, or MPTP intoxication [30, 35, 36]. We therefore tested whether ongoing inflammation was required to initiate BMDC-mediated Treg responses. After two serial adoptive transfers of BMDCs and MPTP intoxication, $\mathrm{T}$ cell and Treg frequencies were assessed in spleens 2 days after MPTP intoxication $[46,49]$. While no changes in CD4+ $\mathrm{T}$ cell frequencies were detected among any treatment group, Treg frequency increased in mice treated with BMDCs prior to MPTP intoxication compared to PBS and MPTP controls (Fig. 8b). These data demonstrated that inflammatory signals are required for BMDC-mediated Treg induction or expansion. Additionally, that the frequency of $\mathrm{CD} 4+$ cells is not changed suggests that BMDCs do not promote Treg proliferation, but rather induce the differentiation of existing CD4+ cells into Tregs.

\section{Discussion}

We and others showed that GM-CSF increases Treg numbers and function [28, 30, 35]. In models of neurodegeneration such as PD, Alzheimer's disease (AD), traumatic brain injury (TBI), and stroke, administration of GM-CSF has been shown to be neuroprotective $[36,52]$. Additionally, adoptive transfer of Tregs from naive or GM-CSF treated donors is neuroprotective [35]. In a recent phase 1 clinical trial, treatment of PD patients with human recombinant GM-CSF (sargramostim) increased Treg numbers and Treg-mediated suppression of CD3/ CD28-induced proliferation compared to placebotreated PD patients [36]. Moreover, sargramostim improved motor deficits and initiation of motor activity as determined by diminished UPDRS, III scores and $\beta$-ERD signals by magnetoencephalography. These data underscore the potential for immune transformation by GMCSF to diminish neurodegeneration in PD.

As $\mathrm{T}$ cells express few, if any, GM-CSF receptors, intermediaries are needed to affect Treg function. Several possible intermediary cell types include dendritic cells (DCs), macrophages, microglia, astrocytes, or myeloid-derived suppressor cells [53-57]. Based on recent data supporting the involvement of tolerogenic DCs in regulation of Treg activity, we chose to first examine the effects of GM-CSF on DCs to combat neuroinflammation and protect dopaminergic neurons. We also assessed the effects on DC-induced Treg formation by proteins that are oxidatively-modified and/or misfolded in PD, such as $\mathrm{N}-\alpha-\mathrm{Syn}$. 


\section{a}

\begin{tabular}{|c|c|c|}
\hline Symbol & MPTP & BMDCs + MPTP \\
\hline CCL3 & 15.4 & 14.1 \\
\hline CXCL10 & 9.6 & 10.7 \\
\hline CCL4 & 8.6 & 6.7 \\
\hline IL1R1 & 7.3 & 6.7 \\
\hline IL1RN & 7.0 & 13.0 \\
\hline CEBPB & 5.7 & 4.4 \\
\hline TLR2 & 2.7 & 3.6 \\
\hline CSF1 & 2.1 & 2.1 \\
\hline IL6RA & 1.8 & 2.0 \\
\hline LTA & 1.7 & 2.9 \\
\hline CXCL2 & 1.7 & 2.2 \\
\hline CXCR2 & 1.6 & 2.8 \\
\hline IL10 & 1.6 & 2.7 \\
\hline CCL1 & 1.6 & 3.0 \\
\hline CRP & 1.6 & 2.3 \\
\hline CXCL1 & 1.6 & 2.3 \\
\hline CXCR1 & 1.6 & 2.3 \\
\hline IL17A & 1.6 & 2.3 \\
\hline IL9 & 1.6 & 2.3 \\
\hline KNG1 & 1.6 & 2.3 \\
\hline CXCL3 & 1.6 & 2.6 \\
\hline TNF & 1.5 & 3.2 \\
\hline IL5 & 1.5 & 2.5 \\
\hline CXCL9 & 1.5 & 2.7 \\
\hline CD40LG & 1.5 & 2.2 \\
\hline CCR4 & 1.5 & 2.6 \\
\hline SELE & 1.5 & 3.4 \\
\hline CCR2 & 1.4 & 2.6 \\
\hline IL7 & 1.4 & 2.3 \\
\hline IL6 & 1.3 & 2.6 \\
\hline CCL20 & 1.1 & 2.1 \\
\hline CCL24 & 1.1 & 2.4 \\
\hline CXCL5 & -1.1 & 2.4 \\
\hline CCL8 & -1.2 & 2.5 \\
\hline C3AR1 & -2.4 & -1.3 \\
\hline MYD88 & -2.5 & -1.3 \\
\hline TLR1 & -2.6 & -1.0 \\
\hline CCL2 & -2.8 & 1.8 \\
\hline CCR3 & -2.9 & -1.5 \\
\hline CCR1 & -3.0 & -1.1 \\
\hline TLR9 & -3.5 & -1.2 \\
\hline CCL11 & -3.6 & -1.0 \\
\hline CXCR4 & -3.8 & -2.3 \\
\hline CCL25 & -4.0 & -2.7 \\
\hline CCL12 & -4.5 & 1.3 \\
\hline RIPK2 & -5.9 & -2.6 \\
\hline TLR3 & -12.8 & -3.1 \\
\hline & & \\
\hline
\end{tabular}

b

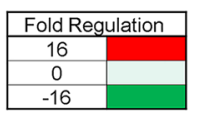

Fig. 7 Gene expression in midbrain after treatment with MPTP or BMDCs and MPTP. BMDCs were differentiated for 8 days in 20 ng/ml GM-CSF prior to 3 days of pretreatment in media alone. These BMDCs were transferred i.v. one and two weeks prior to intoxication with four doses of $16 \mathrm{mg} / \mathrm{kg}$ MPTP. Two days after intoxication, PBS, MPTP and BMDC + MPTP mice were sacrificed and the brain was removed, hemisected and the midbrain was incubated in RNAlater for $24 \mathrm{~h}$ prior to freezing at $-80^{\circ} \mathrm{C}$. RNA was isolated from the midbrain, converted to CDNA PCR arrays of proinflammatory genes were run. a Gene expression was determined relative to the PBS control midbrains; $n=3$ for PBS and $n=4$ for MPTP and MPTP+BMDCs. Fold change was determined using SA Bioscience software. $\mathbf{b}$ Ingenuity Pathway Analysis was used to determine the expression of genes associated with the inflammatory response in BMDCs + MPTP midbrain compared to MPTP control mice

First, bone marrow cells propagated in GM-CSF produce $\mathrm{CD} 11 \mathrm{~b}+\mathrm{CD} 11 \mathrm{c}+$ cells with low expression of $\mathrm{MHC}$ II and CD86. The relative lack of cytokines and chemokines and relatively high levels of CD39 and CD73 associated with purinergic signaling that is important for switching immune cells to anti-inflammatory phenotypes, suggested these cells were of an immature DC phenotype and putatively tolerogenic capable of inducing Tregs [41]. To test that possibility, we found that co-culture of BMDCs with CD4+ T cells induced T cells with a CD4+CD25 ${ }^{\text {hi }}$ Foxp3+ Treg phenotype. Additionally, those phenotypic Tregs were shown to have Treg function as they inhibited CD3/CD28-induced proliferation of $\mathrm{CD} 4+\mathrm{CD} 25$ - Tresp co-cultures in a dose-dependent fashion. Moreover, the function of BMDC-induced Tregs was significantly greater than that observed from fresh splenic isolates, and supported the tolerogenic capacity of the BMDCs. While GM-CSF can yield a heterogeneous mixture of myeloid cells, including BMDCs and macrophages, the tolerogenic capability to induce Tregs has not been ascribed to GM-CSFgenerated macrophages [58, 59], thus the BMDCs described herein are congruent with prior results that demonstrate Treg-inducing capacity by tolerogenic DCs $[31,60]$. Notably, tolerogenic BMDCs further exposed to media, GM-CSF, N- $\alpha$-Syn, or both GM-CSF and N- $\alpha$ Syn were capable of inducing significant increases in Treg numbers compared to starting isolates of primary CD4+CD25- T cells or those stimulated via CD3/CD28.

In clinical trials of GM-CSF in PD, Crohn's Disease, or $\mathrm{AD}[36,61,62]$ (NCT01409915), treatment regimens use extended or chronic GM-CSF administration to maintain selective pressure on the anti-inflammatory response or Treg induction and function. In our model of 

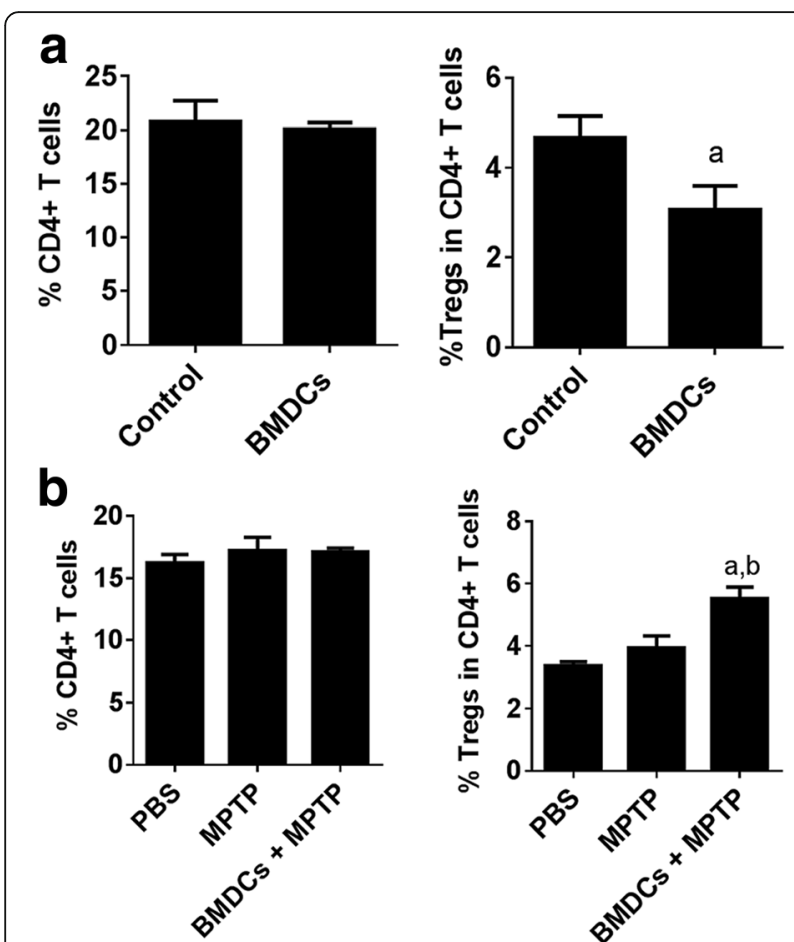

Fig. 8 Acute inflammation induces Tregs after adoptive transfer of tolerogenic BMDCs. GM-CSF-generated BMDCs were cultured in media, harvested, and $1.5 \times 10^{6}$ in $0.25 \mathrm{mls}$ were adoptively transferred i.v. at each of 2 weekly transfers and the frequencies of splenic CD4+ cells and CD4+CD25+Foxp3+ Tregs were evaluated by flow cytometric analysis. Gates were drawn to include $>98 \%$ of the total lymphocytes or $>98 \%$ of CD4+ T cells. a Splenic T cell frequencies were determined seven days after the second transfer of BMDCs to naïve recipients. Control mice received no BMDCs. Means \pm SEM were determined for control $(n=11)$ and BMDC-transferred mice $(n=17)$ and were evaluated by Student's two-tailed t-test whereby $p \leq 0.05$ compared to ${ }^{a}$ control mice. $\mathbf{b}$ After the second transfer of BMDCs, mice were intoxicated with four $16 \mathrm{mg} / \mathrm{kg}$ doses of MPTP, MPTP alone, or PBS alone. T cell frequencies were determined two days after intoxication. Means \pm SEM were determined for $n=5$ mice per each group and evaluated by one-way ANOVA followed by Tukey's post hoc test whereby $p \leq 0.05$ compared to mice treated with a PBS alone or ${ }^{\mathrm{b}} \mathrm{MPTP}$ alone

extended exposure and/or proinflammatory stimulation, tolerogenic BMDCs were cultured in the presence of media or GM-CSF alone and remained unstimulated or were stimulated with $\mathrm{N}-\alpha$-Syn, an acute proinflammatory stimulus. Compared to media alone, continued culture in GM-CSF yielded few significant effects on surface expression of co-stimulatory molecules or expression of cytokine and chemokine genes and proteins. The few effects included increased expression of Jag-1, IL-10, an anti-inflammatory cytokine released from tolerogenic DCs [31, 39, 40], and IL-9 as well as decreased production of MIG (CXCL9) and MIP2 (CXCL2), suggesting that continued exposure to GM-CSF may maintain the tolerogenic state, particularly in light of increased Jag-1 which has been shown necessary for Treg induction [33, 34, 63]. However, the tolerogenic capacity for inducing Tregs was significantly diminished by $45 \%$ indicating that continued exposure to GM-CSF may eventually lessen the tolerogenic capacity and reduce Treg production.

$\mathrm{N}-\alpha$-Syn is an oxidatively modified and readily misfolded protein found in neuronal inclusions and extraneuronal environments of the brain in patients with $\mathrm{PD}$, Lewy body disease, and multiple system atrophy [64, 65], and is also detected in the cervical lymph nodes by $20 \mathrm{~h}$ after MPTP intoxication [18]. Misfolded N- $\alpha-$ Syn is known to activate microglia as well as other myeloid and APCs of the innate immune system $[18,66]$. While the function of native $\alpha$ Syn remains largely unknown, modified or misfolded $\alpha$-Syn can serve as a neoantigen. Thus, $\mathrm{N}-\alpha$-Syn activation of APCs that process and present modified epitopes of $\alpha$-Syn and transmit proinflammatory signals during $\mathrm{T}$ cell activation, would support breaking or evasion of immunological tolerance leading to induction of effector $\mathrm{T}$ cells and antibody responses to the modified self-protein $[18,66]$. Further, tolerogenic signals with or without modified $\alpha$-Syn not only play a role in Treg induction, but also may influence the emergence of $\mathrm{M} 1 / \mathrm{M} 2$ microglia phenotypes [67].

To assess the effect of N- $\alpha$-Syn on phenotype and function, tolerogenic BMDCs were stimulated with $\mathrm{N}-\alpha$ Syn after culture in media or GM-CSF. Stimulation with $\mathrm{N}$ - $\alpha$-Syn showed significant responses as determined by phenotype and expression of cytokines and chemokines regardless of extended culture in media or GM-CSF. Compared to non-stimulated BMDCs, stimulation with $\mathrm{N}-\alpha$-Syn increased surface expression of MHC II, CD86, and Jag-1 co-stimulatory molecules and genes for the maturation markers Cd40, Cebpb, and Ccr7. Additionally, proinflammatory gene expression and protein secretion were increased for IL-1 $\beta$, IL-23 $\alpha$, IL-6, IFN- $\gamma$, TNF$\alpha$, IP-10 (CXCL10), LIX (CXCL5), MIG (CXCL9), MIP2 (CXCL2), and RANTES (CCL5). Together these data show that N- $\alpha$-Syn stimulation drives BMDC pathways to a proinflammatory profile and suggests that differentiation might favor production of mature type 1 DCs that preferentially lead to induction of effector $\mathrm{T}$ cells, such as Th1 or Th17. Unexpectedly, co-culture of N- $\alpha$-Synstimulated BMDCs with CD4+ T cells induced levels of Tregs that approached those attained upon culture in media alone, and significantly greater than those after culture GM-CSF alone. The possibility exists that acute or intense inflammatory responses may provide yet another signal or mechanism by which tolerogenic BMDCs induce conversion of conventional $\mathrm{T}$ cells to Tregs despite an otherwise proinflammatory environment.

Continued culture of BMDCs with GM-CSF followed by $\mathrm{N}-\alpha-$ Syn stimulation diminished several phenotypic 
and functional responses, but not others. Of note, surface expression of CD86 and MHC II were diminished, but Jag-1 was increased to the highest levels of all culture conditions. Expression of proinflammatory cytokine and chemokine genes by BMDCs were overall elevated compared to culture in media alone, though were slightly diminished compared to those stimulated with $\mathrm{N}-\alpha-$ Syn alone. More importantly, production and secretion of proinflammatory proteins were significantly increased over levels induced by $\mathrm{N}-\alpha$-Syn alone included IL-1 $\alpha$, IL-1 $\beta$, IL-2, IL-5, IL-9, IL-12p70, and IL-17, but decreased LIX (CXCL5), MIG (CXCL9). Few antiinflammatory mediators, such as IL-10, were increased. Together, these data suggest that BMDCs in the presence of GM-CSF and N- $\alpha$-Syn induce an overall proinflammatory environment and may not be conducive for Treg development. Indeed, co-culture of CD4+ T cells with BMDCs previously treated with GM-CSF and stimulated with $\mathrm{N}-\alpha-\mathrm{Syn}$, proved to induce the least number of Tregs with the exception of stimulating with anti$\mathrm{CD} 3 / \mathrm{CD} 28$ beads alone.

Overall, GM-CSF-induced BMDCs acquire an immature phenotype and exhibit a high degree of tolerogenic activity based on the ability to induce Tregs. That activity is maintained even after stimulation with a proinflammatory stimulus such as $\mathrm{N}-\alpha-\mathrm{Syn}$ and an elevated proinflammatory state. However, continued exposure to GM-CSF and possibly other mediators, result in a semimature state with diminished tolerogenic capability regardless of stimulation status. Both semi-mature and tolerogenic DCs have the ability to support transformation of CD4+ $\mathrm{T}$ cells to become Tregs [53], but at different levels depending on the state of activation. Indeed, while Treg induction capacity was least robust with semi-mature BMDCs produced by culture with GM-CSF and stimulated with $\mathrm{N}-\alpha-\mathrm{Syn}$, levels of Tregs inducted were significantly greater than those within the initial isolation of $\mathrm{CD} 4+\mathrm{T}$ cells or after CD3/CD28 stimulation. Previous work demonstrated that Jag-1 and OX40L are necessary for BMDC induction of Tregs [33]. However, under the conditions tested, no changes in the surface expression of OX40L were detected. This would suggest that expression of OX40L at the reported levels is sufficient to support Treg induction. Continued culture of tolerogenic BMDCs in GM-CSF increases surface expression of Jag-1, but diminishes their capacity to induce Tregs. This seemingly contrasts reports that Treg induction is dependent on Jag-1 dose and Notch interactions as determined by blocking antibodies or notchsignaling inhibitors [33]. Our data indicate that increases in Jag-1 surface expression were not sufficient to promote additional Treg induction, but were indirectly correlated (Pearson $r=0.55, p=0.06, \mathrm{~F}=4.42, \mathrm{DFn}=1.0$, $\mathrm{DFd}=10.0)$. This suggests that i) Jag-1 expression, albeit at low levels, is sufficient to promote Treg induction, ii) Jag-1 expression beyond a specific threshold provides negative signaling to inhibit Treg induction, or iii) other BMDC cell surface or internal signaling interactions are involved.

In PD models, administration of GM-CSF increases Treg number and function, attenuates inflammation in the brain, and protects dopaminergic neurons along the nigrostriatal axis $[35,51]$. In light of our results showing Treg induction mediated by BMDCs, we tested whether tolerogenic BMDCs could also serve as another mechanism to provide protection from MPTP-mediated neurodegeneration. Indeed, adoptive transfer of GM-CSF-induced BMDCs prior to MPTP intoxication attenuated neuroinflammation and protected dopaminergic neurons along the nigrostriatal axis. Most interestingly, gene expression of proinflammatory mediators in the midbrain were overall increased compared to those from midbrains of mice treated with MPTP alone. These data suggested that adoptive transfer of BMDCs alter the chemokine environment, which in turn may change immune cell recruitment in brain. This is consistent with changes in chemokine gene expression in the substantia nigra of GM-CSF-pretreated mice [35]. However, gene changes also are indicative of decreased inflammation with down-regulation of $I l 1 r 1$, the gene encoding the receptor for IL-1 $\alpha$ and IL-1 $\beta$ which transduces signals intracellularly [68], Cebpb, a transcription factor which induces TNF expression [69], and chemokine genes $\mathrm{Ccl} 3 \mathrm{l3}$ and $\mathrm{Ccl} 4$, which promote inflammation [70] and leukocyte recruitment into the brain [71]. Ccl24 encodes a chemokine released from M2 macrophages which can recruit $\mathrm{T}$ cells, especially Tregs [72, 73]. In glioblastoma multiforme, $C c l 2$ is important for Treg recruitment into the brain and may perform a similar function after MPTP intoxication [74, 75]. Il1rn prevents the recruitment of IL-1 receptor associated protein to IL-1 receptor which is required for transduction of signals within the cell [76], therefore its increased expression, combined with downregulation of Il1r1 would diminish IL- $1 \alpha$ and IL-1 $\beta$ signaling. Together with results showing diminished reactive microglia in Fig. 6, further support the notion that BMDCs diminish neuroinflammation.

As GM-CSF increases Treg numbers [35], we assessed the ability of tolerogenic BMDCs to induce Tregs after adoptive transfer. Unexpectedly, in naïve mice, Treg frequencies diminished after transfer. The causes for these results remain unclear, but may be in part due to limited numbers of BMDCs $\left(1.5 \times 10^{6}\right)$ that could be safely transferred. Another possibility is that without inflammatory insult, induction of Tregs may be inactive or suppressed. Our results suggested that BMDCs may not function by the same mechanism(s) as GM-CSF or that GM-CSF has effects independent of DC-mediated Treg induction. The possibility that GM-CSF or BMDCs 
are protective apart from the induction of Tregs is also suggested. Indeed, GM-CSF can directly promote the survival of PC12 neurons and primary neurons from $\mathrm{MPP}+$ neurotoxicity [51] and could increase other regulatory immune cells such as myeloid-derived suppressor cells (MDSCs) [56]. Interestingly, the possibility that endogenous induction of Tregs by BMDCs within the bone marrow cannot be ruled out as a small population $(<0.5 \%)$ of $\mathrm{CD} 4+\mathrm{CD} 25+$ Foxp3+ Tregs constitute the bone marrow stem cell population which was shown to be neuroprotective in a rat model of experimental stroke [52]. Such alternative mechanisms should be examined in future studies. Because the adoptive transfer of BMDCs was protective in the MPTP model, it may be possible that the adoptive transfer of tolerogenic bone marrow-derived or monocyte-derived dendritic cells may promote Treg induction and decrease PD-associated motor symptoms. It may be possible to induce, expand or prime autologous DCs ex vivo for adoptive transfer as a personalized therapeutic modality to elicit clinical benefits.

\section{Conclusion}

GM-CSF-induced BMDCs have tolerogenic properties that culminate in the transformation of conventional CD4+ $\mathrm{T}$ cells to Tregs. These exhibit higher levels of activity than Tregs from fresh spleen isolates. Continued culture of BMDCs in GM-CSF and/or stimulation with $\mathrm{N}-\alpha$-Syn diminishes the capability to transform Tregs. Continued exposure to GM-CSF reduces the BMDC capability to transform $\mathrm{T}$ cells to Tregs. Adoptive transfer of tolerogenic BMDCs attenuated neuroinflammation as determined by reduced numbers of reactive microglia and protected dopaminergic neurons and their striatal termini from MPTP-induced neurodegeneration. In contrast to in vitro results whereby tolerogenic BMDCs readily convert conventional $\mathrm{T}$ cells to Tregs, adoptive transfer of BMDCs to naïve animals diminished numbers of splenic Tregs; however, acute inflammatory signals by MPTP-intoxication after adoptive transfer of BMDCs significantly increased Treg numbers. Together, these data demonstrate a role for DCs in modulating inflammation and subsequent neurodegeneration. The results also provide another mechanism by which GM-CSF modulates innate immune function to further regulate adaptive immunity and provide neuroprotection. Moreover, administration of GM-CSF or other agents that induce tolerogenic DCs leading to increases in numbers of Tregs and Treg activity, present an attractive therapeutic strategy for decreasing neuroinflammation in autoimmune or neurodegenerative diseases.

\section{Abbreviations}

APCs: Antigen-presenting cells; BMDCs: Bone marrow-derived dendritic cells; BSA: Bovine serum albumin; CFSE: Carboxyfluorescein succinimidyl ester; DAB: 3,3'-diaminobenzidine; DCs: Dendritic cells; DPBS: Dulbecco's phosphate-buffered saline; FSB: Flow stain buffer; GM-CSF: Granulocytemacrophage colony-stimulating factor; HBSS: Hanks' balanced salt solution; i.v.: Intravenous; MDSCs: Myeloid-derived suppressor cells; MFI: Mean fluorescent intensity; MPTP: 1-methyl-4-phenyl-1,2,3,6-tetrahydropyridine; Na-Syn: nitrated alpha synuclein; PBS: Phosphate-buffered saline;

PD: Parkinson's disease; RBCs: Red blood cells; s.c.: subcutaneous;

TBI: Traumatic brain injury; Teffs: Effector T cells; TH: Tyrosine hydroxylase;

TLRs: Toll-like receptors; Tregs: Regulatory T cells; Tresps: Responder T cells;

UPDRS: Unified Parkinson's disease rating scale

\section{Acknowledgements}

We would like to acknowledge Katherine Olson, Krista Namminga, Sam Johnson, Johnathan Herskovitz, Chaoran Ji, Keith Prive, and X. Isabel Heifetz Ament for excellent technical assistance. We would also like to thank the UNMC flow cytometry research facility for their assistance in collecting and analyzing flow cytometric analysis. We would like to thank Michelle Kramer for critical reading of the manuscript.

\section{Funding}

This work was supported, in part, by the University of Nebraska Foundation, which includes donations from the Carol Swarts, M.D. Emerging

Neuroscience Research Laboratory, the Margaret R. Larson Professorship, and the Frances and Louie Blumkin and Harriet Singer Research Foundations, the Vice Chancellor's Office of the University of Nebraska Medical Center for Core Facility Developments, the Michael J. Fox Foundation, and National Institutes of Health grants P01 DA028555, R01 NS36126, P01 NS31492, 2R01 NS034239, P01 MH64570, P01 NS43985, P30 MH062261, and R01 AG043540 (HEG), and R01 NS070190 (RLM). Additional support came from UNMC fellowship (CRS).

\section{Availability of data and materials}

The data sets presented in these studies are available upon request to the corresponding author.

\section{Authors' contributions}

CRS, RLM, and HEG designed experiments. CRS performed experiments. CRS and RLM, interpreted results and performed statistical analysis. CRS, RLM, and HEG prepared the manuscript. All authors read and approved the final manuscript.

\section{Ethics approval}

There are no human participants in these studies.

All animal procedures were performed in agreement with the National Institutes of Health guidelines and were approved by the University of Nebraska Medical Center Institutional Animal Care and Use Committee.

\section{Competing interests}

The authors declare that they have no competing interests.

\section{Publisher's Note}

Springer Nature remains neutral with regard to jurisdictional claims in published maps and institutional affiliations.

Received: 12 December 2017 Accepted: 2 May 2018

Published online: 21 May 2018

\section{References}

1. Olanow CW, Stern MB, Sethi K. The scientific and clinical basis for the treatment of Parkinson disease (2009). Neurology. 2009;72:S1-136.

2. de Lau LML, Breteler MMB. Epidemiology of Parkinson's disease. Lancet Neurol. 2006;5:525-35.

3. McGeer PL, Itagaki S, Akiyama H, McGeer EG. Rate of cell death in parkinsonism indicates active neuropathological process. Ann Neurol. 1988; 24:574-6.

4. Gerhard A, Pavese N, Hotton G, Turkheimer F, Es M, Hammers A, Eggert K, Oertel W, Banati RB, Brooks DJ. In vivo imaging of microglial activation with [11C](R)-PK11195 PET in idiopathic Parkinson's disease. Neurobiol Dis. 2006; 21:404-12. 
5. Depboylu C, Stricker S, Ghobril JP, Oertel WH, Priller J, Hoglinger GU. Brainresident microglia predominate over infiltrating myeloid cells in activation, phagocytosis and interaction with T-lymphocytes in the MPTP mouse model of Parkinson disease. Exp Neurol. 2012;238:183-91.

6. Wu DC, Jackson-Lewis V, Vila M, Tieu K, Teismann P, Vadseth C, Choi DK, Ischiropoulos $\mathrm{H}$, Przedborski S. Blockade of microglial activation is neuroprotective in the 1-methyl-4-phenyl-1,2,3,6-tetrahydropyridine mouse model of Parkinson disease. J Neurosci. 2002;22:1763-71.

7. Orr CF, Rowe DB, Halliday GM. An inflammatory review of Parkinson's disease. Prog Neurobiol. 2002:68:325-40.

8. Mogi M, Harada M, Kondo T, Riederer P, Inagaki H, Minami M, Nagatsu T. Interleukin-1 beta, interleukin-6, epidermal growth factor and transforming growth factor-alpha are elevated in the brain from parkinsonian patients. Neurosci Lett. 1994;180:147-50.

9. Blum-Degen D, Müller T, Kuhn W, Gerlach M, Przuntek H, Riederer P. Interleukin-1 beta and interleukin- 6 are elevated in the cerebrospinal fluid of Alzheimer's and de novo Parkinson's disease patients. Neurosci Lett. 1995;202:17-20.

10. Qureshi GA, Baig S, Bednar I, Södersten P, Forsberg G, Siden A. Increased cerebrospinal fluid concentration of nitrite in Parkinson's disease. Neuroreport. 1995;6:1642-4.

11. Bas J, Calopa M, Mestre M, Molleví DG, Cutillas B, Ambrosio S, Buendia E. Lymphocyte populations in Parkinson's disease and in rat models of parkinsonism. J Neuroimmunol. 2001;113:146-52.

12. Niwa F, Kuriyama N, Nakagawa M, Imanishi J. Effects of peripheral lymphocyte subpopulations and the clinical correlation with Parkinson's disease. Geriatr Gerontol Int. 2012;12:102-7.

13. Saunders JA, Estes KA, Kosloski LM, Allen HE, Dempsey KM, Torres-Russotto DR, Meza JL, Santamaria PM, Bertoni JM, Murman DL, et al. CD4+ regulatory and effector/memory T cell subsets profile motor dysfunction in Parkinson's disease. J Neurolmmune Pharmacol. 2012;7:927-38.

14. Stevens CH, Rowe D, Morel-Kopp MC, Orr C, Russell T, Ranola M, Ward C, Halliday GM. Reduced T helper and B lymphocytes in Parkinson's disease. J Neuroimmunol. 2012;252:95-9.

15. Horvath S, Ritz BR. Increased epigenetic age and granulocyte counts in the blood of Parkinson's disease patients. Aging. 2015;7:1130-42.

16. Baba Y, Kuroiwa A, Uitti RJ, Wszolek ZK, Yamada T. Alterations of Tlymphocyte populations in Parkinson disease. Parkinsonism Relat Disord. 2005;11:493-8

17. Chen Y, Yu M, Liu X, Qu H, Chen Q, Qian W, Wei D, Xu W, Ma B, Wu W. Clinical characteristics and peripheral T cell subsets in Parkinson's disease patients with constipation. Int J Clin Exp Pathol. 2015:8:2495-504.

18. Benner EJ, Banerjee R, Reynolds AD, Sherman S, Pisarev VM, Tsiperson V, Nemachek C, Ciborowski P, Przedborski S, Mosley RL, Gendelman HE. Nitrated alpha-synuclein immunity accelerates degeneration of nigral dopaminergic neurons. PLoS One. 2008:3:e1376.

19. Reynolds AD, Stone DK, Hutter JA, Benner EJ, Mosley RL, Gendelman HE. Regulatory T cells attenuate Th17 cell-mediated nigrostriatal dopaminergic neurodegeneration in a model of Parkinson's disease. J Immunol. 2010;184:2261-71

20. Brochard V, Combadiere B, Prigent A, Laouar Y, Perrin A, Beray-Berthat V, Bonduelle O, Alvarez-Fischer D, Callebert J, Launay JM, et al. Infiltration of CD4+ lymphocytes into the brain contributes to neurodegeneration in a mouse model of Parkinson disease. J Clin Invest. 2009;119:182-92.

21. Mosley RL, Hutter-Saunders JA, Stone DK, Gendelman HE. Inflammation and adaptive immunity in Parkinson's disease. Cold Spring Harb Perspect Med. 2012;2:a009381.

22. Hirsch EC, Hunot S. Neuroinflammation in Parkinson's disease: a target for neuroprotection? Lancet Neurol. 2009;8:382-97.

23. Ghasemi M, Erturk M, Buruk K, Sonmez M. Induction of potent protection against acute and latent herpes simplex virus infection in mice vaccinated with dendritic cells. Cytotherapy. 2013;15:352-61.

24. Vo MC, Lee HJ, Kim JS, Hoang MD, Choi NR, Rhee JH, Lakshmanan VK, Shin SJ, Lee JJ. Dendritic cell vaccination with a toll-like receptor agonist derived from mycobacteria enhances anti-tumor immunity. Oncotarget. 2015;6:33781-90.

25. Hirayama $M$, Nishimura $Y$. The present status and future prospects of peptide-based cancer vaccines. Int Immunol. 2016;28:319-28.

26. Teramoto K, Ozaki Y, Hanaoka J, Sawai S, Tezuka N, Fujino S, Daigo Y, Kontani K. Predictive biomarkers and effectiveness of MUC1-targeted dendritic-cell-based vaccine in patients with refractory non-small cell lung cancer. Ther Adv Med Oncol. 2017;9:147-57.
27. Gross S, Erdmann M, Haendle I, Voland S, Berger T, Schultz E, Strasser E, Danker $P$, Janka R, Schliep $S$, et al. Twelve-year survival and immune correlates in dendritic cell-vaccinated melanoma patients. JCI Insight. 2017;2:e91438.

28. Sheng JR, Muthusamy T, Prabhakar BS, Meriggioli MN. GM-CSF-induced regulatory $T$ cells selectively inhibit anti-acetylcholine receptor-specific immune responses in experimental myasthenia gravis. J Neuroimmunol. 2011;240-241:65-73.

29. Vasu C, Dogan RNE, Holterman MJ, Prabhakar BS. Selective induction of dendritic cells using granulocyte macrophage-colony stimulating factor, but not fms-like tyrosine kinase receptor 3-ligand, activates thyroglobulinspecific CD4+/CD25+ T cells and suppresses experimental autoimmune thyroiditis. J Immunol. 2003;170:5511-22.

30. Cheatem D, Ganesh BB, Gangi E, Vasu C, Prabhakar BS. Modulation of dendritic cells using granulocyte-macrophage colony-stimulating factor (GM-CSF) delays type 1 diabetes by enhancing CD4+CD25+ regulatory $T$ cell function. Clin Immunol. 2009;131:260-70.

31. Ganesh BB, Cheatem DM, Sheng JR, Vasu C, Prabhakar BS. GM-CSF-induced CD11c+CD8a-dendritic cells facilitate Foxp3+ and IL-10+ regulatory $T$ cell expansion resulting in suppression of autoimmune thyroiditis. Int Immunol. 2009;21:269-82.

32. Sainathan SK, Hanna EM, Gong Q, Bishnupuri KS, Luo Q, Colonna M, White FV, Croze E, Houchen C, Anant S, Dieckgraefe BK. Granulocyte macrophage colony-stimulating factor ameliorates DSS-induced experimental colitis. Inflamm Bowel Dis. 2008;14:88-99.

33. Gopisetty A, Bhattacharya P, Haddad C, Bruno JC Jr, Vasu C, Miele L, Prabhakar BS. OX40L/Jagged1 cosignaling by GM-CSF-induced bone marrow-derived dendritic cells is required for the expansion of functional regulatory T cells. J Immunol. 2013;190:5516-25.

34. Kumar P, Alharshawi K, Bhattacharya P, Marinelarena A, Haddad C, Sun Z, Chiba S, Epstein AL, Prabhakar BS. Soluble OX40L and JAG1 induce selective proliferation of functional regulatory T-cells independent of canonical TCR signaling. Sci Rep. 2017;7:39751.

35. Kosloski LM, Kosmacek EA, Olson KE, Mosley RL, Gendelman HE. GM-CSF induces neuroprotective and anti-inflammatory responses in 1-methyl-4-phenyl1,2,3,6-tetrahydropyridine intoxicated mice. J Neuroimmunol. 2013;265:1-10.

36. Gendelman HE, Zhang $Y$, Santamaria $P$, Olson KE, Schutt CR, Bhatti D, Shetty BLD, Lu Y, Estes KA, Standaert DG, et al. Evaluation of the safety and immunomodulatory effects of sargramostim in a randomized, double-blind phase 1 clinical Parkinson's disease trial. NPJ Parkinsons Dis. 2017;3:10.

37. Olson KE, Kosloski-Bilek LM, Anderson KM, Diggs BJ, Clark BE, Gledhill JM Jr, Shandler SJ, Mosley RL, Gendelman HE. Selective VIP receptor agonists facilitate immune transformation for dopaminergic neuroprotection in MPTP-intoxicated mice. J Neurosci. 2015;35:16463-78.

38. Jackson-Lewis $V$, Przedborski S. Protocol for the MPTP mouse model of Parkinson's disease. Nat Protoc. 2007:2:141-51.

39. Chamorro S, Garcia-Vallejo JJ, Unger WW, Fernandes RJ, Bruijns SC, Laban S, Roep BO, Hart BA T, van Kooyk Y. TLR triggering on tolerogenic dendritic cells results in TLR2 up-regulation and a reduced proinflammatory immune program. J Immunol. 2009;183:2984-94.

40. Naranjo-Gomez M, Raich-Regue D, Onate C, Grau-Lopez L, Ramo-Tello C, Pujol-Borrell R, Martinez-Caceres E, Borras FE. Comparative study of clinical grade human tolerogenic dendritic cells. J Transl Med. 2011;9:89.

41. Antonioli L, Pacher P, Vizi ES, Hasko G. CD39 and CD73 in immunity and inflammation. Trends Mol Med. 2013;19:355-67.

42. Reynolds AD, Banerjee R, Liu J, Gendelman HE, Mosley RL. Neuroprotective activities of CD4+CD25+ regulatory T cells in an animal model of Parkinson's disease. J Leukoc Biol. 2007;82:1083-94.

43. Kohm AP, Carpentier PA, Anger HA, Miller SD. Cutting edge: CD4+CD25+ regulatory $T$ cells suppress antigen-specific autoreactive immune responses and central nervous system inflammation during active experimental autoimmune encephalomyelitis. J Immunol. 2002;169:4712-6.

44. Banerjee R, Mosley RL, Reynolds AD, Dhar A, Jackson-Lewis V, Gordon PH, Przedborski S, Gendelman HE. Adaptive immune neuroprotection in G93ASOD1 amyotrophic lateral sclerosis mice. PLoS One. 2008;3:e2740.

45. Baek H, Ye M, Kang G, Lee C, Lee G, Choi DB, Jung J, Kim H, Lee S, Kim JS, et al. Neuroprotective effects of CD4+CD25+Foxp3+ regulatory T cells in a 3xTg-AD Alzheimer's disease model. Oncotarget. 2016;7:69347-57.

46. Kohutnicka M, Lewandowska E, Kurkowska-Jastrzebska I, Członkowski A, Członkowska A. Microglial and astrocytic involvement in a murine model of Parkinson's disease induced by 1-methyl-4-phenyl-1,2,3,6-tetrahydropyridine (MPTP). Immunopharmacology. 1998;39:167-80. 
47. Breidert T, Callebert J, Heneka MT, Landreth G, Launay JM, Hirsch EC. Protective action of the peroxisome proliferator-activated receptor-gamma agonist pioglitazone in a mouse model of Parkinson's disease. J Neurochem. 2002:82:615-24.

48. Cho Y, Son HJ, Kim EM, Choi JH, Kim ST, Ji IJ, Choi DH, Joh TH, Kim YS, Hwang O. Doxycycline is neuroprotective against nigral dopaminergic degeneration by a dual mechanism involving MMP-3. Neurotox Res. 2009; 16:361-71.

49. Jackson-Lewis V, Jakowec M, Burke RE, Przedborski S. Time course and morphology of dopaminergic neuronal death caused by the neurotoxin 1methyl-4-phenyl-1,2,3,6-tetrahydropyridine. Neurodegeneration. 1995;4:257-69.

50. Gabay C, Lamacchia C, Palmer G. IL-1 pathways in inflammation and human diseases. Nat Rev Rheumatol. 2010;6:232-41.

51. Kim NK, Choi BH, Huang X, Snyder BJ, Bukhari S, Kong TH, Park H, Park HC, Park SR, Ha Y. Granulocyte-macrophage colony-stimulating factor promotes survival of dopaminergic neurons in the 1-methyl-4-phenyl-1,2,3,6tetrahydropyridine-induced murine Parkinson's disease model. Eur J Neurosci. 2009;29:891-900.

52. Neal EG, Acosta SA, Kaneko Y, Ji X, Borlongan CV. Regulatory T-cells within bone marrow-derived stem cells actively confer immunomodulatory and neuroprotective effects against stroke. J Cereb Blood Flow Metab. 2018; https://doi.org/10.1177/0271678X18766172.

53. Rutella S, Danese S, Leone G. Tolerogenic dendritic cells: cytokine modulation comes of age. Blood. 2006;108:1435-40.

54. Hamilton JA, Achuthan A. Colony stimulating factors and myeloid cell biology in health and disease. Trends Immunol. 2013;34:81-9.

55. Liva SM, Kahn MA, Dopp JM, de Vellis J. Signal transduction pathways induced by GM-CSF in microglia: significance in the control of proliferation. Glia. 1999:26:344-52.

56. Dolcetti L, Peranzoni E, Ugel S, Marigo I, Fernandez Gomez A, Mesa C, Geilich M, Winkels G, Traggiai E, Casati A, et al. Hierarchy of immunosuppressive strength among myeloid-derived suppressor cell subsets is determined by GM-CSF. Eur J Immunol. 2010;40:22-35.

57. Sawada M, Itoh Y, Suzumura A, Marunouchi T. Expression of cytokine receptors in cultured neuronal and glial cells. Neurosci Lett. 1993;160:131-4.

58. Helft J, Bottcher J, Chakravarty P, Zelenay S, Huotari J, Schraml BU, Goubau D. Reis e Sousa C. GM-CSF mouse bone marrow cultures comprise a heterogeneous population of $\mathrm{CD} 11 \mathrm{C}(+) \mathrm{MHCll}(+)$ macrophages and dendritic cells. Immunity. 2015;42:1197-211.

59. Na YR, Jung D, Gu GJ, Seok SH. GM-CSF grown bone marrow derived cells are composed of phenotypically different dendritic cells and macrophages. Mol Cells. 2016;39:734-41.

60. Bhattacharya P, Gopisetty A, Ganesh BB, Sheng JR, Prabhakar BS. GM-CSFinduced, bone-marrow-derived dendritic cells can expand natural Tregs and induce adaptive Tregs by different mechanisms. J Leukoc Biol. 2011;89:235-49.

61. Korzenik JR, Dieckgraefe BK, Valentine JF, Hausman DF, Gilbert MJ. Group. SiCsDS. Sargramostim for active Crohn's disease. N Engl J Med. 2005;352: 2193-201.

62. Valentine JF, Fedorak RN, Feagan B, Fredlund P, Schmitt R, Ni P, Humphries TJ. Steroid-sparing properties of sargramostim in patients with corticosteroid-dependent Crohn's disease: a randomised, double-blind, placebo-controlled, phase 2 study. Gut. 2009;58:1354-62.

63. Cahill EF, Tobin LM, Carty F, Mahon BP, English K. Jagged-1 is required for the expansion of CD4+ CD25+ FoxP3+ regulatory T cells and tolerogenic dendritic cells by murine mesenchymal stromal cells. Stem Cell Res Ther. 2015;6:19.

64. Duda JE, Giasson BI, Chen Q, Gur TL, Hurtig HI, Stern MB, Gollomp SM, Ischiropoulos H, Lee VM, Trojanowski JQ. Widespread nitration of pathological inclusions in neurodegenerative synucleinopathies. Am J Pathol. 2000;157:1439-45

65. Giasson Bl. Oxidative damage linked to neurodegeneration by selective alpha -synuclein nitration in synucleinopathy lesions. Science. 2000;290:985-9.

66. Reynolds AD, Stone DK, Mosley RL, Gendelman HE. Nitrated \{alpha\}synuclein-induced alterations in microglial immunity are regulated by CD4+ T cell subsets. J Immunol. 2009;182:4137-49.

67. Tang $Y$, Le W. Differential roles of $M 1$ and M2 microglia in neurodegenerative diseases. Mol Neurobiol. 2016;53:1181-94.

68. Sims JE, Gayle MA, Slack JL, Alderson MR, Bird TA, Giri JG, Colotta F, Re F, Mantovani A, Shaneback K. Interleukin 1 signaling occurs exclusively via the type I receptor. Proc Natl Acad Sci U S A. 1993:90:6155-9.
69. Pope RM, Leutz A, Ness SA. C/EBP beta regulation of the tumor necrosis factor alpha gene. J Clin Invest. 1994;94:1449-55.

70. Yang J, Wang N. Genome-wide expression and methylation profiles reveal candidate genes and biological processes underlying synovial inflammatory tissue of patients with osteoarthritis. Int J Rheum Dis. 2015;18:783-90.

71. Ubogu EE, Cossoy MB, Ransohoff RM. The expression and function of chemokines involved in CNS inflammation. Trends Pharmacol Sci. 2006;27:48-55.

72. Zamarron $\mathrm{BF}, \mathrm{Chen} \mathrm{W}$. Dual roles of immune cells and their factors in cancer development and progression. Int J Biol. 2011;7:651-8.

73. Watanabe K, Jose PJ, Rankin SM. Eotaxin-2 generation is differentially regulated by lipopolysaccharide and IL-4 in monocytes and macrophages. J Immunol. 2002;168:1911-8.

74. Chang AL, Miska J, Wainwright DA, Dey M, Rivetta CV, Yu D, Kanojia D, Pituch KC, Qiao J, Pytel P, et al. CCL2 produced by the glioma microenvironment is essential for the recruitment of regulatory $T$ cells and myeloid-derived suppressor cells. Cancer Res. 2016;76:5671-82.

75. Jordan JT, Sun W, Hussain SF, DeAngulo G, Prabhu SS, Heimberger AB. Preferential migration of regulatory $T$ cells mediated by glioma-secreted chemokines can be blocked with chemotherapy. Cancer Immunol Immunother. 2008;57:123-31.

76. Dinarello CA. Immunological and inflammatory functions of the interleukin1 family. Annu Rev Immunol. 2009;27:519-50.

\section{Ready to submit your research? Choose BMC and benefit from:}

- fast, convenient online submission

- thorough peer review by experienced researchers in your field

- rapid publication on acceptance

- support for research data, including large and complex data types

- gold Open Access which fosters wider collaboration and increased citations

- maximum visibility for your research: over $100 \mathrm{M}$ website views per year

At BMC, research is always in progress.

Learn more biomedcentral.com/submissions 